\title{
AN ANATOMICAL AND EXPERIMENTAL STUDY OF THE CEREBELLAR NUCLEI AND THEIR EFFERENT PATHWAYS IN THE MONKEY
}

\author{
ROBERT WHEELER RAND \\ Laboratory of Comparative Neurology, Department of Anatomy, \\ University of Michigan, Ann Arbor \\ FTPTEEN FIGURES \\ INTRODUCTION
}

Since the middle of the 19th century the extensive works and resultant discoveries of anatomists and physiologists have been unveiling the architecture and functions of the primate cerebellum with its associated nuclei and efferent tracts. Today the general concensus is that the cerebellum is concerned with the coordination of voluntary and/or involuntary action of striated musculature or, as Tilney ('19) expressed it, the production of synergia between agonistic and antagonistic muscle groups. The distribution pattern of the efferent fibers of the cerebellar nuclei affords an anatomical foundation for the interpretation of this functional or physiological result. These efferent fibers, which leave the cerebellum predominantly through the superior cerebellar peduncles, but also by way of the restiform bodies, terminate directly or indirectly in association with the motor pathways of vestibular, tegmental, tectal, pallidal, striatal and cortical origin.

The present investigation was undertaken with the supposition that this pattern of distribution to motor centers, or correlating areas, is the predominant cerebellar pattern and that the efferent fiber systems from the primate cere- 
bellar nuclei should be intimately related with all important extrapyramidal motor systems of the central nervous system. Among other new connections, it has been possible to find those of the cerebellum with the nuclei of such extrapyramidal systems as the medial longitudinal fasciculus and the dorsal longitudinal fasciculus.

The author wishes to express his sincere appreciation to Professor'Elizabeth C. Crosby under whose guidance and unending assistance this study was planned and executed. $\mathrm{He}$ is grateful to the sponsors of the Alphonso Morton Clover Medical Research Fund and the Otolaryngological Research Fund of the University of Michigan Medical School which financed this investigation.

\section{MATERIAL AND METHODS}

The species of monkeys used for the experimental portions of this study were Macaca mulatta and Macacus cynomolgus. Although 7 animals were experimented upon, only 4 are reported herein; the remaining three died of a dysentery (with which many monkeys are infected on arrival in this country) shortly after the operation. The normal anatomy of the cerebellar nuclei of Macaca mulatta was reviewed in preparations from the Huber Comparative Neurological Collection stained by the Weil method ('45) and the Huber modification ('27) of the toluidine blue technique. The experimental material was prepared by the Marchi method using the Swank and Davenport ('35) modification. The utilization of this technique affords only visualization of degenerating myelinated fibers. All fibers become amyelinated at some distance proximal to their termination, a fact which must receive consideration in drawing conclusions.

In series one, two and three a suboccipital craniectomy was performed aseptically under intravenous pentothal and/ or ether anesthesia. The size of the exposure varied. The dural incisions were closed whenever possible and the sub- 
occipital musculature and fascia tightly approximated in anatomical layers to provide protection before suturing the skin. The McCulloch stereotaxic instrument was used in series 4 after aseptically making appropriate trephines under ether anesthesia. The lesions of the deep cerebellar nuclei and the superior cerebellar peduncles were produced by an insulated needle through which a mild cauterizing electric current was passed. In all instances preoperative and postoperative testing of the animals was carried out and included examination of the reflexes, the muscle tone, the cranial nerves, and the ability of the monkey to perform gross and fine movements of the trunk and extremities.

All the monkeys presented here were sacrificed between the 14th and 20th postoperative days. After inducing surgical anesthesia with ether, their thoracic cavities were rapidly opened bilaterally and their arterial systems perfused with 500 to $1,000 \mathrm{~cm}^{3}$ of $10 \%$ formalin. The brains with attached cervical cord were removed carefully; in all instances the fixation was excellent.

\section{EXPERIMENTAL ANIMALS}

\section{Monkey $I$}

The subject of this experiment was a normal Macacus cynomolgus male of $4 \frac{1}{2}$ pounds $(2.0 \mathrm{~kg})$. On October 1, 1951, under ether anesthesia, a bilateral suboccipital craniectomy was performed with direct exposure of the vermis and the medial portions of both cerebellar hemispheres. The exposed cerebellum appeared normal. A slim electrode needle, insulated except for the tip, was inserted into the right side of the pyramis and directed into the right nueleus fastigii; 3.5 milliamperes of electrical cauterizing current were passed through this needle for 30 seconds before it was removed. No gross bleeding occurred. Recovery from the operation was uneventful, and immediate postoperative testing revealed occasional nystagmoid movements on right lateral gaze.

On subsequent postoperative examinations over the next 14 days nystagmus was not evident on conjugate gaze in any direction. Nystagmus could not be produced even though the monkey was revolved rapidly, first to the left and then to the right, with his head in a horizontal plane. The extraocular muscles showed neither 
paralysis nor paresis, and reflex and voluntary conjugate gaze were normal in all spheres. The museular tonus in the extremities remained normal, as did the deep tendon reflexes. The monkey was able to run, climb and jump well. He showed no evidences of cerebellar disturbance, except for moderate retropulsion during the first 24 hours. Examination of the cranial nerves revealed nothing unusual. Stimulation of the plantar surface of the feet evoked no pathological response.

After sacrificing the monkey on October 15, inspection of the brain showed the exterior of the cerebellum, cerebrum and brain stem to be normal except for a $5 \mathrm{~mm}$ circular area of yellowish discoloration on the surface of the pyramis of the vermis, the site where the insulated electrode had been inserted. There was neither intracerebellar hemorrhage nor infection of the wound.

The lesion (figs. 1,2 and 3) as studied in Marchi preparation is small and localized. It begins at the most caudal end of the right nucleus fastigii involving the medioventral quadrant of that nucleus and also the inferior cerebellar commissure. As the lesion is followed rostrad, the medial half of the posterior third of the nucleus is included; at this level the lesion attains its maximum size (fig. 2). It then decreases in area, and, in the middle third of the nucleus is present only in the medioventral quadrant (fig. 3). At the junction of the rostral and middle thirds of the nucleus fastigii the lesion ceases leaving the rostral third of the nucleus uninvolved.

The degenerated fibers leave the right nucleus fastigii by several clear-cut routes. The greatest number first turn directly dorsad, partially through the nucleus but especially along its medial border; upon reaching the dorsal surface of the nucleus they arch sharply laterad, to the left and right, dispersing cephalad in the medullary stratum dorsal to the interpositus nucleus and dorsolateral to the dentate nucleus on either side (figs. 2 and 3), but with more crossed than uncrossed fibers. This pattern can be observed at all levels of the lesion.

Within the cerebellum, from the ventral surface of the right nucleus fastigii, degenerated fascicles stream ventrolaterad to the right and left beneath the interpositus and dentate nuclei (fig. 1) to enter the floceular lobe on either side. They are particularly numerous and evident on the side of the lesion, and are limited exclusively to these lobules.

\section{Monkey II}

This macaque (Macacus mulatta) was a healthy, normal young female weighing 5 pounds $(2.25 \mathrm{~kg})$. On September 27,1951 , a left suboceipital craniectomy was performed under a combined intra- 
venous pentothal and open drop ether anesthesia. The dura was normal in appearance as was the posterior inferior surface of the left cerebellar hemisphere. At the junction of the tonsillar lobe with the biventral lobule, $2 \mathrm{~cm}$ lateral to the midline, a fine insulated needle was inserted in the direction of the dorsal portion of the left dentate nucleus. Three milliamperes of cautery current were passed through the needle for 45 seconds before it was removed. The cerebellum remained normal in appearance and continued to pulsate; there was no gross evidence of hemorrhage. The postoperative recovery was uneventful.

Postoperatively the monkey sat in a normal position; the head remained upright without tilting abnormally to either side. The extraocular muscles appeared to function well and voluntary conjugate movements of the eyes in all directions of gaze remained normal. Neither nystagmus nor nystagmoid movements developed. Although the monkey seemed reluctant to walk, run and jump for the first 24 hours she did so thereafter in a normal fashion. There was no evidence of ataxia or dysequilibrium in her gait. She was observed many times using both hands when eating or scratching. Except for clumsiness of the left hand for the first postoperative day no abnormalities such as tremor, hypermetria, hypometria or ataxia were noted in either upper or lower extremities. The reflexes remained equal and normal throughout; the muscle tonus was good. Facial movements were symmetrical and no abnormalities were found in the remaining cranial nerves.

At necropsy the wound had healed well without evidence of infection. A small portion of the left tonsillar lobe had herniated approximately $1 \mathrm{~cm}$ through the open dura. Just beneath the cortex of the paramedian and biventral lobules a small hemorrhage, $5 \mathrm{~mm}$ in diameter, was present lateral to the needle tract. The cerebrum, brain stem and cervical spinal cord were normal grossly.

The lesion, small and localized, starts at the caudal end of the left dentate nucleus, which is completely involved. It reaches its greatest size at the junction of the middle and caudal thirds of the nucleus, of which it involves approximately the middle third of the medial half (fig. 4), and then decreases in size to end at the junction of the middle and rostral thirds of the dentate nucleus (fig. 5) after having shifted dorsally to include in its extent the dorsomedial portion of the most medial areas of this nuclear mass. The rostral third and lateral areas of the left dentate nucleus are normal. There is no degeneration in either nucleus interpositus, nucleus fastigii, or the right dentate nucleus.

Degenerated fibers surround the entire caudal third of the left dentate nucleus and pass rostrally, increasing in number as the lesion 
increases in size. At the rostral tip of the lesion (fig. 5) these degenerated fibers form a rather compact bundle in the hilus of the dentate nucleus. They pass ventrad and then ventromediad and rostrad, to enter the left superior cerebellar peduncle (fig. 6) where they occupy its middle third dorsoventrally. The degeneration is more concentrated on the medial border of the peduncle. Those fibers which lie within the cerebellum, far on the periphery of the dentate nucleus, turn medioventrad as this nucleus decreases in size, to join the fascicles from the hilus of the dentate nucleus. No decussation of fibers is found within the cerebellum.

\section{Monkey III}

A healthy Macacus cynomolgus female of 4 pounds $(1.8 \mathrm{~kg})$ was the subject of a bilateral suboccipital craniectomy under intravenous sodium pentothal anesthesia on June 12, 1951. After opening the dura on the left, exposure of the entire inferior surface of this normal hemisphere was accomplished. A thin insulated needle was inserted into the hemisphere in the direction of the left dentate nucleus. Six milliamperes of electric current were passed through the needle for 90 seconds before it was removed. The wound was closed in layers after suturing the dura. No obvious bleeding was produced in making the lesion. The monkey made an uneventful recovery from the operation.

During the first three postoperative days the monkey sat with a wide base, her left forearm farther from the midline than the right and her right side leaning against the cage. Even in this squatting position the entire body swayed forward and backward; her head position was not constant and tended to tilt to the left or to the right. She was unable to run, walk or elimb effectively and such movements were accompanied by wild swaying and falling, usually to the left. The body was earried close to the floor of the eage with the extremities spread apart, representing a crawling rather than a walking motion. Preference was given to the right upper extremity when reaching for the side of the cage or for food; movements of the left upper extremity were jerky and tremulous. Although the monkey showed ataxia of this extremity when earrying food to the mouth, there was neither noticeable hypermetria, hypometria, nor decomposition of movement. There was questionable terminal tremor. Full range of the extraocular muscles was present on voluntary and reflex testing, and no nystagmus of any type was observed. The facial movements were normal on both sides. Paresis of the extremities was not present. The deep reflexes were somewhat decreased throughout and moderate hypotonus seemed to be present in the left extremities, 
although this was difficult to evaluate. An attempt at jumping was disastrous, as she would undershoot the distance and fall to the floor. During the fall she was unable to correct her position and landed indiscriminately upon her back or sides and occasionally on her head.

By the 5th postoperative day she showed improvement in walking and climbing and fell less frequently when jumping. Otherwise the findings were essentially unchanged.

A continued steady improvement was shown from the 9th postoperative day to June 26,1951 , the time of sacrifice and preparation by the Marchi staining technique. At this time she was able to jump almost normal distances without falling, and could climb with facility. The body was still carried low to the ground when walking or running, with a tendency to turn toward the left and occasionally to fall in that direction. Neither tremor with movement or at rest, nor nystagmus were noted.

Gross examination of the brain at postmortem revealed the cerebrum and the cerebellum to be normal, except for a small area of yellowish discoloration at the site of the needle puncture. Relatively speaking, the lesion produced in this series is extensive. Most caudally it involves the ventral portions of the left dentate and interpositus nuclei. At the level of the 8th nerve it includes the dorsomedial quadrant of the inferior cerebellar peduncle, the lateral edge of Deiters' nucleus and part of the superior vestibular nucleus. At levels slightly farther forward the most rostral portion of the inferior cerebellar peduncle is destroyed as it enters the cerebellum. From this point the lesion progressively decreases continuing to involve the ventral areas of the dentate and interpositus nuclei and then passes into the dorsal half of the brachium conjunctivum where it terminates just before the decussation. The roof nuclei are not involved, and the interpositus and dentate nuclei are normal on the right. The left brachium conjunctivum shows complete degeneration.

\section{Monkey IV}

On February 4, 1950, a small trephine opening in the right parietooccipital region was made just lateral to the midline in this 5 pound $(2.25 \mathrm{~kg})$ male Macaca mulatta. The Horsley-Clark stereotaxic instrument was employed and the insulated needle was directed into the right superior cerebellar peduncle. A cauterizing current of three milliamperes was passed through the needle for 60 seconds before it was removed. Sodium pentothal was given and recovery was uneventful.

Although the elinical findings and postoperative course simulated those of monkey III, the disequilibrium was less marked, and, further, 
there was no tremor of the extremities, either at rest or during movement. This animal also had a very small lesion in the dorsal superior portion of the left superior cerebellar peduncle and left trochlear nerve made previously by another investigator whose results are to be published. Fourteen days after the first lesion was produced, the animal was sacrificed in preparation for the Marchi staining technique.

The external appearance of the cerebral hemispheres, cerebellum and brain stem was normal. There are three distinct lesions. The first, a small lesion, starts at the ventromedial tip of the right dentate nucleus and extends approximately $1 \mathrm{~mm}$. At the level of the 8 th nerve the second, a spherical lesion, involves the dorsal half of the inferior cerebellar peduncle and the lateral border of the lateral vestibular nucleus on the right. This latter lesion extends dorsad and cephalad into the base of the cerebellum including the inferior tip of the right dentate nucleus together with a portion of the superior vestibular nucleus and its immediate adjoining area. Farther rostrad, the lesion involves the superior cerebellar peduncle and the ventral spino-cerebellar tract as the former enters the cerebellum. The third lesion is very discrete and spherical, located on the left at the site where the trochlear nerve lies just dorsal to the brachium conjunctivum. It involves only the most dorsal tip of the superior cerebellar peduncle, the mesencephalic root in this region and the trochlear nerve fibers. The right brachium conjunctivum shows dense degeneration in its dorsal half and ventral tip ; however, only scattered degeneration is seen between these portions (fig. 12). The serial sections prepared from this monkey's brain did not continue above upper midbrain levels.

\section{DESCRIPTION OF MICROSCOPIC MATERIAL}

\section{Microscopic anatomy of the cerebellar nuclei}

Since the early investigations of Stilling $(1867,1878)$, who described and illustrated the cerebellar nuclei in man as nucleus fastigii, globosus, emboliformis and dentatus, many investigators have continued to divide the central cerebellar gray of the monkey into 4 nuclei rather than accept the terminology proposed by Brunner ('19) for the monkeynamely, nucleus fastigii (medial), nucleus interpositus, and nucleus dentatus (lateral). Brunner stated that further subdivision of nucleus interpositus into nucleus emboliformis and nucleus globosus was impossible below the apes (Simia), 
and that in the monkey the three nuclear masses fuse in various planes.

In the present material, the cerebellar nuclei of Macaca mulatta, as studied in transverse serial sections stained with toluidine blue and also by the Weil methods, are large masses of neurons located on either side of the midline within the medullary portion of the cerebellum. The dentate nucleus first comes into focus caudally as a small circular mass within the caudolateral portion of this medullary stratum. It enlarges rapidly into a hemispherical form with its convex border directed laterally and is completely surrounded by myelinated fibers. Then an acellular space containing myelinated fibers develops within the solid gray mass of cells (fig. $7 \mathrm{~A}$ ) giving rise to the configuration of a capital $D$ or its mirror image. At this level along the middle third of the medial border of the dentate and in intimate association with it, a mass of neurons appears (fig. $7 \mathrm{~B}$ ) which is the beginning of nucleus interpositus. This extends progressively dorsad (figs. $7 \mathrm{C}, \mathrm{D}$ ) as the sections are followed forward through the series. It attains a dorsal level comparable to that of the more lateral portions of the dentate.

At caudal levels of nucleus interpositus, the dentate nucleus shows a small indentation in the middle third of its lateral surface (fig. $7 \mathrm{~B}$ ). A large indentation or hilus develops on the dorsal border of the nucleus and connects the more centrally placed acellular space inside the nucleus with the surface; thus giving a characteristic $U$ shape to the dentate (fig. $7 \mathrm{C}$ ). In the meantime, the nucleus interpositus has increased rapidly and become oval. It remains as a solid mass of gray distinctly separated from the dentate by medullated fascicles.

Although the dentate maintains the form just described as the sections are traced forward, the nucleus interpositus. develops a notch in its dorsolateral angle into which fibers pass (fig. $7 \mathrm{C}$ ). It is here, just lateral to the midline, that the nucleus fastigii appears as an ovoid cluster of cells (figs. $7 \mathrm{~B}, \mathrm{C}$ ). This configuration of the cerebellar nuclei 
persists for a short distance. However, a union soon occurs between the middle portion of the medial border of the dentate and the lateral border of the interpositus (figs. $7 \mathrm{C}, \mathrm{F}$ ) and two hilus form - one directed ventrally and the other dorsally between these nuclei. At this level the dentate nucleus has increased lateroventrally (figs. $7 \mathrm{C}, \mathrm{F}$ ) and the nucleus fastigii has reached its maximum size maintaining its somewhat circular outline.

In a slightly more cephalic direction, the dentate nucleus again separates from the nucleus interpositus by another hilus which appears on the ventral surface of the former nucleus (figs. $7 \mathrm{C}, \mathrm{D}$ ). Despite a reduction in depth and width, the dorsal hilus of the dentate still persists. Thus, the gray that was intimately attached to the dentate in lower planes (fig. $7 \mathrm{~B}$ ) becomes closely associated with the interpositus (fig. $7 \mathrm{D}$ ) at more rostral planes and, in addition, there is a continuous bridge of cells between the nucleus fastigii and the most medioventral area of the interpositus nucleus.

Upon superficial examination the nucleus fastigii seems to be divided into two secondary groups: a large medial mass and a smaller lateral area (figs. $7 \mathrm{C}, \mathrm{F}$ ). However, slightly more rostral sections show that again the groups unite into a compact cell mass toward the upper extent of the cerebellar nuclei (figs. $7 \mathrm{D}, \mathrm{E}$ ).

Higher planes reveal the nucleus interpositus as gradually being broken up by heavily medullated fibers which run through it in a dorsolateral direction. The ventral portion of the nucleus interpositus is completely broken up by fibers (figs. $7 \mathrm{C}-\mathrm{E}$ ). A cap remains on the dorsomedial tip of the dentate, which now has the form of an incomplete letter $C$ or its mirror image, and its hilus is directed mediad (fig. $7 \mathrm{E}$ ). This cap might be regarded to represent the nucleus interpositus but, after having followed the sections, the present writer concluded that it should rightfully be considered a mediodorsal division of the dentate. 
At these levels another group of rather compact cells overlies the roof of the 4 th ventricle for a short distance. The mass appears pear-shaped with the apex directed mediodorsad and is located beneath the dentate from which it is separated by myelinated fibers. There seems to be no direct connection with the nuclear groups of the vestibular complex or the cerebellum, although this mass is placed intermediate between them, and probably represents what Brunner ('19) called the gray margin zone. The neurons within this mass are very similar to those in the dentate nucleus.

The dentate slowly continues to diminish and its associated cap decreases even more gradually until both are represented only by oval masses of gray, which finally disappear. At this level the brachium conjunctivum forms between and medial to them. The nucleus fastigii ceases slightly before the nucleus dentatus and nucleus interpositus.

Thus, from this material, it can be seen that the pattern of the nuclear masses conforms in general to the description of Brunner ('19). However, several points are worth emphasis. The author believes that the exact boundaries between the nucleus dentatus and the nucleus interpositus are very indefinite and vary markedly between caudal and rostral levels of these nuclei. In caudal sections, the vertical medial limb of the dentate, which has been likened to the letter $U$ in these planes (figs. $7 \mathrm{~B}, \mathrm{C}$ ), is clearly separated from the ovoid nucleus interpositus and is connected with the more lateral area of the dentate only at its ventral extremity. In more rostral planes, where a hilus develops in the ventral surface of the dentate, this vertical medial limb of the dentate is completely separated from the lateral limb and becomes intimately attached to the lateral portion of the nucleus interpositus (fig. $7 \mathrm{D}$ ). In the most cephalic areas it forms a cap on the mediodorsal portion of the dentate, which now appears as the letter $C$ or its mirror image (fig. $7 \mathrm{E}$ ).

Cellular bridges are found in several planes connecting the ventral surface of the nucleus fastigii to the ventral surface of the nucleus interpositus (fig. $7 \mathrm{C}$ ) and, although 
the Weil stain gives the impression that the nucleus fastigii can be divided at midplanes into two nuclei (fig. $7 \mathrm{~F}$ ), the toluidine blue stain of comparable levels does not confirm this fact.

The neurons of the dentate nucleus show little variation in size but because of their multiangular, triangular and spindle shapes cannot be measured accurately — the average diameter is approximately $30 \mu$. A distinct, centrally located nucleus and, in many, a prominent nucleolus can be observed. In midareas where the nuclear gray shows a definite hilus, the cells tend to be more spindle-shaped and align themselves in irregular rows radiating from the inner border (figs. $7 \mathrm{~B}-\mathrm{E})$. However, in more rostral or caudal regions, where a hilus is not prominent this polarity is not so distinct, and the cells become dispersed uniformly throughout the dentate. In these regions the majority are multiangular rather than spindle-shaped. Small glial cells, which are very deeply stained and average $7-10 \mu$ in diameter, intermingle with the neurons throughout the dentate nucleus. In this material it is not possible to subdivide this nucleus morphologically.

The neurons of the nucleus interpositus are quite similar to those of the dentate nucleus but some of them tend to be polygonal. They do not arrange themselves in rows but rather in groups or disperse equally throughout the gray with a variation from level to level. There are, in addition, a few cells which are larger than those of the dentate nucleus measuring up to $40 \mu$ and tending to occur in groups. Small, darkly stained glial cells are also present throughout this nucleus. Here again no subdivision is possible on a morphological basis.

In the nucleus fastigii some of the neurons are comparable to the largest found in the nucleus interpositus and nucleus dentatus; others are small, multiangular cells of 16-20 $\mu$ in diameter. Each cell type tends to be arranged in groups or clusters rather than to be intermingled - this is not necessarily true for all planes, however. As was the case in the nucleus interpositus, the neurons of the nucleus fastigii are 
not arranged in rows. The small glial cells are interdispersed about equally throughout the entire nucleus.

Therefore, it would seem reasonable, as evidenced by the literature and the material available for this study, to consider the cerebellar nuclei in the monkey as divisible basically into a medial and a lateral nucleus, which is in accord with a general functional medial and lateral subdivision as observed by Allen ('24) in the guinea pig; Tilney ('27), Sachs and Fincher ('27), Mussen ('27) and Magoun, Hare and Ranson ('35) in the monkey. For the present further subdivisions of the cerebellar nuclei of the monkey should be limited to those described by Brunner ('19). Tilney ('27) stated that the medial complex (nucleus fastigii and nucleus globosus) is for the archikinetic function of balance and the lateral group (nucleus dentatus and nucleus emboliformis) is concerned with the neokinetic functions of skilled movements and is particularly associated with the development of the hand. The embryologic studies by Dowd ('29) of the dentate and intermediate nuclei of the pig indicate that these nuclei have similar fundamental functions in this ungulate.

Although Jansen and Brodal ('40) believed that the paraflocculus is connected with the ventrolateral part of the dentate nucleus in the cat and the rabbit, Clarke and Horsley ('05) did not find this connection in their study of the cerebellum of the cat, the dog and the monkey, but found, rather, that the paraflocculus was connected with the nucleus fastigii. However, Jansen and Brodal ('40) agreed that, in general, the more medial parts of the complex were older than the more lateral regions. In the pig embryo Dowd ('29) noted that the nucleus interpositus undergoes earlier development than does the dentate nucleus, thus the dentate portion of the lateral nuclear group would be ontogenetically younger in this form than the nucleus interpositus. The present author, although aware of the necessity for more extensive experimentation upon the lateral areas of the dentate nucleus, regards the lateral and the ventrolateral region of this nucleus 
(fig. 7) in the monkey as representing a more recent development.

\section{Brachium conjunctivum}

In a beautifully illustrated article, van Gehuchten ('05a) strongly emphasized that for the rabbit "les pédoncules cérébelleux supérieurs sont indépendants de l'écorce grise cérébelleuse." Further, "si la lésion est limitée aux masses cérébelleuses, les dégénérescences se localisent exclusivement dans les pédoncules cérébelleux supérieurs." and "L'origine principale de ces fibers nerveuses se trouve dans le noyau dentelé." Prior to this time most authors, with the notable exceptions of Thomas (1897, dog), Klimoff (1899, rabbit), Orestano ('01, dog and cat) and Clarke and Horsley ('05, cat, dog and monkey), believed that the cerebellar cortex also contributed fibers directly to the brachium conjunctivum (or superior cerebellar peduncle). However, more recently Sachs and Fincher ('27), in studies of the monkey, described fibers passing directly into the superior cerebellar peduncle to the region of the red nucleus and the basal ganglia. Hohman ('29) stated that in the cat there were no efferent fibers from the cerebellar cortex to the brain stem, except from the anterior vermis to Deiters' nucleus. Jansen and Brodal ('40), from studies of cerebellar cortical lesions in the cat and rabbit, concurred with Clarke and Horsley and Hohman regarding the origin of the direct efferent fibers from the cerebellar cortex to the brain stem. Allen ('24), Mussen ('27) and Rasmussen ('33) have shown that following localized lesions within the dentate and intermediate nuclei of the cerebellum of the guinea pig, monkey and cat respectively, the degenerated fibers leave exclusively by way of the ipsilateral superior cerebellar peduncle.

In series two of the present material the degenerated fibers from the localized lesion of the dentate nucleus pass out of the cerebellum via the ipsilateral brachium conjunctivum; lesions limited exclusively to the cerebellar cortex were not studied. The ascending limb of the uncinate fasciculus of 
Russell, which arises from the contralateral nucleus fastigii, partially intermingles with the superior cerebellar peduncle prior to its decussation. This fasciculus is considered in detail with the fastigio-bulbar tracts.

After the fibers of the brachium conjunctivum leave the cerebellum, an aberrant group of degenerated fascicles at the dorsal tip of the peduncle sweeps through the mesencephalic root of the trigeminal nerve to pierce the midlateral border of the periventricular gray in isthmus and lower inferior collicular levels and then arch ventromediad, along the ventral regions of this gray, to the dorsolateral border of the medial longitudinal fasciculus (fig. 12). At this point, a division occurs with approximately one-half of the fibers turning ventrad through the medial longitudinal fasciculus and then mediad to decussate; the remaining half continues within the periventricular gray to the dorsomedial border of the medial longitudinal fasciculus where they also turn sharply ventrad and then mediad to cross the midline. During this course, the fascicles distribute to the nuclear masses of the periventricular gray. These connections are considered further with dento-periventricular fibers (p. 188).

The earliest investigators recognized that the fibers within the superior cerebellar peduncle cross within the commissure of Wernekinck. There were some, however, including Marchi (1892) and Russell (1895) who, after studying dogs and monkeys, felt that the decussation was incomplete and still others, among them Ferrier and Turner (1894, macaque), Thomas (1897), Klimoff (1899), Orestano ('01), Lewandowsky ('03, rabbit) and van Gehuchten ('05a), who maintained that the fibers crossed completely. Many investigators have since confirmed the observations of these latter authors, and the findings in the present material (fig. 9) do substantiate the complete decussation of the brachium conjunctivum.

Although Ramón y Cajal ('11), after studying various mammals including the guinea pig, rat and man, described the more dorsal fibers of the brachium conjunctivum as crossing first, in the present series the most ventral fibers of the 
brachium decussate initially by arching ventrad and then mediocephalad (fig. 12); almost concomitantly, those of the dorsal regions cross in a step-like fashion (fig. 8) as they pass cephalad. Finally, the central portion decussates; its most dorsal area crossing in a manner similar to that shown by the dorsal third of the superior cerebellar peduncle, and its most ventral part like the ventral third of the peduncle. During the decussation the ventral half of the superior cerebellar peduncle is loosely spread out but the dorsal half remains rather compact. The decussation commences at the ponto-isthmal region and is not complete until upper midbrain levels (fig. 9).

Following decussation, the brachium conjunctivum gives rise to an ascending and a descending limb - brachium conjunctivum ascendens (figs. 10, 11) and descendens (figs. 12, 13). This pattern was observed by most of the early investigators including Marchi (1892), Thomas (1897), Lewandowsky ('03), van Gehuchten ('05a) and others.

Brachium conjunctivum ascendens. The dento-rubral tract is in reality a dento-tegmental system but early investigators gave it this title because of its specific termination in the red nucleus of Stilling. Allen ('24, guinea pig) recognized that, prior to decussation, the superior cerebellar peduncle also "supplied the dorsal and lateral formatio-reticularis with a number of fibers" and, furthermore, that after decussation these fibers were distributed to the "formatio-reticularis dorsal to the red nucleus." Castaldi ('23, guinea pig) and Crosby and Woodburne ('43, in monkey) have described a series of nuclear groups within the tegmental gray of the midbrain: pars lateralis, pars intermedia, pars dorsalis and pars ventralis of the nucleus mesencephalicus profundus. It can be demonstrated in the present material that prior to the decussation of the brachium conjunctivum, some fibers terminate in pars ventralis and pars lateralis of the nucleus mesencephalicus profundus (fig. 8) and in the tegmental portion of the laterodorsal tegmental nucleus. Following decussation, degenerated fibers are found in the nucleus mesen- 
cephalicus profundus pars ventralis throughout its extent and are greater in number than in the uncrossed distribution to the same area. Pars lateralis of the nucleus mesencephalicus profundus also has crossed degenerated fibers in relation to its cells although the number of such fibers in this material is less than those terminating in pars ventralis.

It is believed that some fibers and/or their collaterals in the superior cerebellar peduncle contribute, before or after decussation, to pars dorsalis and pars intermedia of the nucleus mesencephalicus profundus, since these portions are completely surrounded by degenerated fascicles. Before decussation there is a contribution to the marginal nuclei of the superior cerebellar peduncle.

Although Forel (1881, rat and rabbit) and other early investigators recognized that destruction of the superior cerebellar peduncle produced atrophy of the cells in the posterior part of the red nucleus on the side opposite the lesion and Marchi (1892, dog and monkey), Ferrier and Turner (1894, monkey) and others were able to demonstrate degenerated fibers terminating in the contralateral red nucleus as a result of partial or total extirpation of a cerebellar hemisphere, van Gehuchten ('05a, rabbit) emphasized that these fibers had their origin in cells within the central gray masses of the cerebellum and that uncrossed fibers to the red nucleus did not exist.

Hatschek ('07) and Ariëns Kappers ('21) pointed out for various mammals that the red nucleus had two types of cells and that it consisted of two major portions - a caudal or magnocellular and a rostral or parvocellular part. In addition, these investigators noted that the large-celled portion was greater in size in the lower mammalian forms and the small-celled part larger in the higher forms. Mingazzini ('28) also found these divisions in man. Crosby and Woodburne ('43) described the red nucleus in the monkey and found that the caudal pole of the magnocellular part lay in planes at the midregion of the oculomotor nuclear complex and the rostral limit of the parvocellular portion invaded slightly 
the diencephalon, medial and ventromedial to the zona incerta. Nissl preparations suggested to these latter investigators that the parvocellular part was made up of correlative cells and the magnocellular portion of efferent neurons. They stressed the great increase in size of the parvocellular portion and the marked decrease of neurons in the magnocellular portion in the monkey and man as compared to those in subprimate forms.

Allen ('24), Mussen ('27) and Rasmussen ('33), using Marchi preparations of the guinea pig, monkey and cat respectively, demonstrated that, following lesions in the dentate and intermediate nuclei of the cerebellum, crossed ascending fibers within the brachium conjunctivum distributed to all parts of the red nucleus. Their conclusions did not support either the views of Marburg ('24) that the fibers from the emboliform nucleus terminated in the magnocellular portion of the red nucleus and that the fibers from the dentate went only to the parvocellular portion and to the thalamus, or the findings of Hatschek ('07) who described the superior cerebellar peduncle as divided into an inner part, which had fibers from the globosus and emboliform nuclei to the magnocellular portion of the red nucleus, and an outer portion, which carried dento-rubral fibers to the parvocellular area of this nucleus. Mussen concluded, after counting the number of fibers leaving nucleus emboliformis and dentate nucleus respectively, that one-half of the fibers ended in the magnocellular portion, one-quarter in the parvocellular portion of the red nucleus, and that the remaining fibers continued into the diencephalon of the macaque.

It can be clearly shown from the available material that the fibers in the superior cerebellar peduncle, after decussating, terminate partially in both portions of the red nucleus on the side opposite the lesion. Although no discrete lesion was produced in the nucleus interpositus, the degenerated fibers from the small lesion in the medial portion of the dentate nucleus in series 2 (figs. 4 and 5) also ended, in part, within the magno- and parvocellular portions of the red nu- 
cleus (figs. 9 and 10). In this particular series, as in series 3 , no direct, uncrossed dento-rubral fibers could be seen (fig. 9 ); in series 4 the peduncular lesions had been made on both sides. It should be emphasized that the fastigial nucleus does not contribute fibers to either portion of the red nucleus. The Marchi technique precludes an accurate count of the degenerated fibers. Mussen stated that his computations were rough totals, consequently no attempt was made to count them in the material for this paper. Nevertheless, it is the author's impression that considerably more than onequarter of the total number of fascicles from the nucleus interpositus and the dentate nucleus continue cephalad beyond the red nucleus into the diencephalon (fig. 11).

Many of the earlier investigators, including Thomas (1897), Probst ('02), Ramón y Cajal ('04) and van Gehuchten ('05a), agreed that, in the superior cerebellar peduncle, some fibers from the lateral cerebellar nuclei, after decussating, terminated beyond the red nucleus in the thalamus. During and since that time specific areas of termination within the thalamus have been suggested by many investigators and any attempt to compare the thalamic terminations, as pointed out by Dow ('42), is complicated by the variations in nomenclature, as well as by the wide range of species used for the experimentation. For clarification of nomenclature, the present author suggests the descriptions of Ariëns Kappers, Huber and Crosby ('36) and Walker ('38a). Thomas (1897, dog) demonstrated fibers to the external nucleus of the thalamus. Probst ('02, dog and cat) believed that the thalamic termination was in the ventral nuclei of the dorsal thalamus; von Monakow ('10, monkey) that it was in his medial thalamic nucleus; Horsley and Clarke ('08, monkey) that the fascicles passed to the lateral thalamic nuclei; Vogt, C. ('09, monkey) to the intermediate ventral nucleus; Sachs ('09, monkeys and cats), to the centromedian and lateral nuclei; Ramón y Cajal ('11), to the noyau anterior (nucleus ventralis pars anterior); Allen ('24), to the medial division of the nucleus ventralis thalami; Foix and Nicolesco ('25), to the ventral and posterior 
parts of their noyau externe of man; Mussen ('27), to the posterior median region of the ventral nucleus; Ranson and Ingram ('32, cat), to the pars externa of the ventral nucleus and the arcuate nucleus; Clark (' 36 , macaque), to the dorsal and rostral parts of the pars externa of the ventral nucleus. More recently Crouch and Thompson ('38, monkey) traced the pathway to the nucleus ventralis intermedius of the dorsal thalamus and Walker ('38a, b, monkey and chimpanzee) to the nucleus ventralis lateralis but also to the anterior part of the nucleus ventralis posterior. Walker ('38a) has also described uncrossed fibers to the nucleus ventralis lateralis.

In the present material the degenerated fibers to the dorsal thalamus are completely crossed and they terminate in three areas: the ventral nucleus (nucleus ventralis lateralis), the medial nuclei (centromedian and dorsomedial) and the midline nuclei. As the dento-thalamic fibers pass rostrad beyond the red nucleus to attain the field of Forel, they divide roughly into 4 bundles, two of which are rather large and conspicuous. One of these fascicles passes dorsorostrad to break up through the centromedian, dorsomedial nuclei and in their immediate vicinity (fig. 11); however some of these fibers continue forward and laterad to enter the nucleus ventralis lateralis. Such a termination in the medial nuclei was also observed by Sachs ('09) and by Gerebtzoff ('36, rabbit). However, Clark ('36) and Walker ('38a) thought that the centromedian nucleus did not receive fibers from the cerebellar nuclei, superior cerebellar peduncle or, for that matter, terminal fascicles from any caudal levels of the brain stem (Clark, '36). They regarded the degenerated fibers traced into the centromedian nucleus as representing only isolated fibers of passage, destined for the nucleus ventralis lateralis to which the thalamic termination of the dento-thalamic tract in the primate was exclusively restricted.

A second bundle of rather compact fascicles passes laterorostrad through the $\mathrm{H}_{1}$ field of Forel and the nucleus ventralis posterior of the dorsal thalamus (fig. 11) into the nucleus ventralis lateralis. This distribution of fibers throughout 
the nucleus ventralis lateralis, without much overlapping in the nucleus ventralis posterior, is in accord with the results of Allen ('24, guinea pig), Ranson and Ingram ('32, cat), Clark ('36, monkey) and Walker ('38a, b, monkey and chimpanzee).

Fascicles of the third group, derived from the most medial fibers which entered the centromedian nucleus and from a medial bundle of fibers in the field of Forel, join loosely together to distribute to the midline gray of the dorsal thalamus (fig. 11). Thomas (1897) believed that a small number of fibers from the superior cerebellar peduncle terminated in the posterior extremity of the internal nucleus of the thalamus in the dog. Ranson and Ingram ('32) stated that ascending fibers might pass to the midline nuclei in the cat. Such a connection is distinctly apparent in the present material. The fibers are distributed throughout the midline gray and represent part of a large system of cerebello-periventricular gray connections. Although no connections are found to the hypothalamus, terminations occur in the ventral thalamus.

The 4th bundle of degenerated fibers to leave the field of Forel (fig. 11) course laterad into the nucleus of this field and to the zona incerta. Beyond this point they cannot be traced. Domenico (1899, man), an early Italian investigator, described two sets of fibers associated with the superior cerebellar peduncle. One bundle entered the zona incerta where some of the fascicles took part in forming the capsule of the body of Luys and the ansa of the lenticular nucleus. Fibers of the second bundle passed to the dorsal thalamus. Allen ('24) traced a rather large number of fibers from the ascending limb of the superior cerebellar peduncle into the zona incerta of the guinea pig, contrary to the results of Probst ('02) and others who denied that any fibers of this tract distributed either to the nucleus of Luys or to the zona incerta in the dog and cat.

As observed in this experimental material, the periventricular gray distribution of degenerated fibers from lesions 
in the dentate nucleus and superior cerebellar peduncle is limited to mesencephalon and to diencephalon. Under the description of the decussation of the brachium conjunctivum there was a discussion of an aberrant group of peduncular fascicles which enter the periventricular gray before decussation (fig. 12). These, which arise from the dentate nucleus, distribute caudal to their decussation to the periventricular portion of the laterodorsal tegmental nucleus, pars centralis and pars lateralis of the dorsal nucleus of the raphe and the caudal linear nucleus. Probably a few fascicles also enter the medial longitudinal fasciculus but none are seen to distribute to the ipsilateral nuclei of the trochlear or oculomotor nerves. After the decussation of the fibers within the superior cerebellar peduncle, another group of fascicles, derived mostly from those lying ventral or ventromedial to the red nucleus but also a few from the dorsolateral area, pass dorsad to enter the periventricular gray throughout the upper mesencephalon (fig. 10) and the most caudal areas of the diencephalon. These fibers terminate in the region of the interstitial nucleus of the medial longitudinal fasciculus, the nucleus of Darkschewitsch, the nucleus of the posterior commissure, the nucleus parvocellularis aquaeductus annuli, the Edinger-Westphal nucleus (caudal portion) and the region of the dorsal longitudinal fasciculus. The distribution of degenerated fascicles into the midline gray of the dorsal thalamus, as described under the dento-thalamic tract, is part of this large cerebello-periventricular system.

Most anatomists concur that, in some areas, the distribution of fascicles from the nucleus interpositus is almost coincidental to that of the dentate nucleus; therefore it might be postulated that they are similar in their central gray terminations.

\section{Brachium conjunctivum descendens}

Orestano ('01) and, later, Ramón y Cajal ('03) described two descending tracts of cerebellar origin within the brain stem. Ramón y Cajal designated them as "vía cerebelo- 
espinal homolateral ó externa" and "vía cerebelo-espinal cruzado ó interna," and believed that they were formed respectively by a bifurcation of some of the fibers within the superior cerebellar peduncle before and after decussation. He thought that the peduncular fibers which gave rise to the homolateral tract probably did not provide fascicles to the contralateral descending system and, furthermore, that the cells of origin were in the dentate and perhaps, also, in the fastigal nucleus. Van Gehuchten ('05a) could not demonstrate the homolateral cerebello-spinal tract of Ramón y Cajal and stated that the crossed cerebellar-spinal tract should be called "cerebello-bulbaire croisée," thus confirming the previous observations of Thomas (1897). Van Gehuchten agreed with Ramón y Cajal that this tract arose from a bifurcation of the fibers of the superior cerebellar peduncle; however, Wallenberg (1898) thought that it was not formed by a bifurcation but rather was a distinctly separate tract. Allen ('24) accepted Wallenberg's concept as regards the origin of the bundle, but did not agree that it contributes to the nucleus of the hypoglossal nerve. Allen ('24), Mussen ('27) and Rasmussen ('33), using various animals, have contributed to our knowledge of this bundle. These last authors concurred with van Gehuchten ('05a) that the brachium conjunctivum descendens was a completely crossed tract lying dorsal to the medial lemniscus and that it decreased in size as it passed caudad. Rasmussen ('33) described the tract as ending at the level of the nucleus olivaris inferior and, like Allen ('24), as distributing to the ventral and median reticular formation of the pons and the medulla oblongata.

The brachium conjunctivum descendens, as illustrated in monkeys II, III and IV, confirms the descriptions of van Gehuchten, Allen, Rasmussen and others. After its origin from the nucleus dentatus and probably from the nucleus interpositus it descends through the superior cerebellar peduncle to cross completely at lower midbrain levels. In monkeys III and IV it can easily be traced into the hilus of the chief inferior olivary nucleus (fig. 13) throughout the extent 
of the nucleus and also to the medial and the dorsal accessory olivary nuclei. This distribution appears to represent almost the entire final termination of the brachium conjunctivum descendens; however, a few degenerated fascicles continue mediocaudad to the chief inferior olivary nucleus and possibly extend into the upper cervical cord levels.

In the tegmentum of the midbrain and the isthmus regions, the brachium conjunctivum descendens lies dorsomedial to the rubro-spinal tract, just lateral to the midline (fig. 12); in the pons it occupies a position dorsal to the medial lemniscus and, in the medulla oblongata, it is dorsomedial to the olivary complex (fig. 13). The tract decreases in size slowly but progressively as it descends, contributing throughout its course to the tegmental and reticular gray in its immediate vicinity. As emphasized by Allen ('24), there is no evidence that any of its fibers end in the efferent nuclei of the cranial nerves.

A pattern of distribution of the efferent fibers arising from the neurons of the nucleus dentatus and nucleus interpositus and leaving the cerebellum through the superior cerebellar peduncle is strongly suggested from the combined evidence of other investigators and the findings in this material. In the monkey Mussen ('27) found that, following localized lesions in the dorsocephalic portion of the nucleus emboliformis (interpositus) and in the dorsocephalic portion of the dentate nucleus, degenerated fibers passed into the ipsilateral brachium conjunctivum with those from the nucleus emboliformis at the dorsomedian tip and those from the dentate nucleus in a central position. Demolé ('27) believed that in man the fibers from the dorsomedian (microgyric) portion of the dentate nucleus entered the dorsomedian section of the superior cerebellar peduncle. In the present material with a localized lesion of the caudomedial portion of the dentate nucleus (fig. 4) degenerated fascicles lie in the central portion of the brachium conjunctivum (fig. 6). Therefore, it seems probable that the ventral portions of the superior cerebellar peduncle are made up of fibers from the ventral areas of the 
nucleus interpositus and from the ventral and lateral parts of the dentate nucleus.

The fibers of the brachium conjunctivum ascendens to the mesencephalon and diencephalon appear to have a pattern of distribution. Probst ('02) noted that those fascicles in the more ventral portion of the superior cerebellar peduncle remained ventral to the red nucleus, the dorsal fascicles from the peduncle were more lateral to it. Data from the available material demonstrate that the distribution of the dorsal fibers of the superior cerebellar peduncle is mainly to the dorsolateral areas of the red nucleus; some, however, are found ventral to and within the ventral part of the nucleus itself. From a lesion in the middle portion of the caudal twothirds of the dentate nucleus (fig. 4), the distribution to the nucleus ventralis lateralis appears to be only about equal to that terminating in the centromedian, dorsomedial and midline nuclei taken together. By contrast, in complete degeneration of the superior cerebellar peduncle, the distribution of the fascicles to the nucleus ventralis lateralis of the dorsal thalamus is proportionately greater than to the other thalamic areas. Although Mussen ('27) believed that only one-quarter of the fibers continued beyond the red nucleus to the thalamus, the material available from this study shows that considerably more than this number terminate in the diencephalon. All of these facts taken together suggest that the nucleus ventralis lateralis receives its additional fibers from the lateral and ventrolateral areas of the dentate, that is, the more recently developed areas. Probably these portions of the dentate nucleus, although they send a few fibers to the midline and medial nuclei of the dorsal thalamus, distribute mainly to the nucleus ventralis lateralis. This is apparently another manifestation of cephalization within the central nervous system.

Although there is overlap in the distribution of the brachium conjunctivum descendens, again a pattern of termination is evident (figs. 12, 13). In monkey IV the degenerated fascicles from the dorsal tip of the superior cerebellar peduncle pass 
only to the midpons in this tract; however, in monkey II with a localized lesion in the dentate nucleus (fig. 4) the fibers can be traced to lower pontine and upper medullary levels; whereas, with complete degeneration of the superior cerebellar peduncle the tract terminates in the reticular formation of the medulla oblongata and the olivary nuclear complex (fig. 13). Thus the caudal portions of this tract are made up chiefly of fibers from the more ventral regions of the contralateral superior cerebellar peduncle, and are believed to originate from the more lateral and ventrolateral areas of the dentate nucleus and the ventral portions of the nucleus interpositus. The brachium conjunctivum descendens not only demonstrates a cephalocaudal pattern of termination, but those fascicles of it which end at pontine levels exclusively lie dorsolateral in the tract, whereas those fibers which extend to the reticular formation of the medulla oblongata and the inferior olivary nuclear complex occupy a more medioventral position within the bundle (fig. 12).

\section{Fastigio-bulbar tracts}

The efferent fibers which arise in the nuclei fastigii and enter the brain stem have been classified by most investigators as fastigio-bulbar fasciculi. There is such a tract on either side of the midline and within each there are crossed and uncrossed fibers; thus each nucleus fastigii contributes to both fastigio-bulbar tracts. The uncinate fasciculus of Russell (fig. 14) and the fastigio-vestibular fasciculus (fig. 3) comprise the two major components of the fastigio-bulbar system and each of these components has fibers from both fastigial nuclei. It should be stressed that the predominant fibers within each fastigio-bulbar tract are crossed and have a wider distribution than the uncrossed fibers in the same fasciculus. Another important fact is that each fastigiobulbar tract contains fibers which have been named according to their termination, thus, fastigio-reticular, fastigio-vestibular, fastigio-motorius and fastigio-spinal. 
Uncinate fasciculus of Russell. Prominent among the fastigio-bulbar system is the uncinate fasciculus of Russell. The descriptive terms used for this tract include "fasciculus uncinatus" (Lewandowsky, '03), "accessorisches Bindearmbündel" (Probst, '02) and "Le Faisceau en Crochet" (Thomas, 1897, van Gehuchten, '05b). Although it was incompletely described by Russell (1895, dog and monkey) he is generally accredited with its discovery. However, the origin of the tract in the nucleus fastigii was determined accurately by Probst ('02) and van Gehuchten ('05b). The early investigators as well as some of the more recent ones, including Mussen ('27, monkey) and Rasmussen ('33, cat), have stressed the fact that it is an almost completely crossed system of fibers. In studying this tract Rasmussen has also emphasized the importance of making discrete lesions which do not involve the fibers lying dorsal to the nucleus fastigii. In series one, such a lesion was produced (figs. 1, 2, and 3), which shows a rather large uncrossed component to the uncinate fasciculus of Russell, as well as the more generally described crossed component of this fasciculus (fig. 14).

Many authors have divided the uncinate fasciculus into an ascending and a descending limb. The Marchi material from monkey I demonstrates that, although both the crossed and uncrossed components of Russell's fasciculus have descending limbs (figs. 1 and 2), only the crossed part has an ascending limb (fig. 15) which is part of the so-called "accessorisches Bindearmbündel"' which Probst ('02, dog and cat) illustrated. Therefore, Russell's fasciculus can be divided into three major components: (1) a crossed ascending limb, (2) a crossed descending limb and (3) an uncrossed descending limb.

In this study of the macaque no distinction is made between the nucleus fastigii and the nucleus globosus, which are described as separate nuclei in the anthropoid apes and in man and, by most authors, in the monkey. Serial sections of the cerebellar nuclei in Macaca mulatta, as previously described, show no distinct morphological or histological differences within the nucleus fastigii (fig. 7). The conclu- 
sions are compatible with those of Brunner ('19). The manner of escape of the degenerated fibers from the nucleus fastigii, which in the present series represents the origin of the hook bundle or the uncinate fasciculus of Russell, is similar to that described by Rasmussen ('33) in the cat, but not entirely in accord with Mussen ('27), who emphasized the exodus of these fibers from the ventral surface of the nucleus fastigii in the monkey. The greatest number of degenerated fascicles turn dorsad from the region of the lesion in the nucleus fastigii throughout the extent of the nucleus (figs. 2 and 3), sweeping partially through this nucleus but passing mainly along its medial surface. Upon attaining the dorsal surface of the nucleus, they turn sharply laterad to either side spreading out as a broad sheet and then turning cephalad into the medullary stratum dorsal to the interpositus nuclei and dorsolateral to the dentate nuclei. More of these fibers are crossed than uncrossed (figs. 2 and 3). It is difficult to state whether or not any of the fibers which pass partially through the ipsilateral nucleus interpositus and nucleus dentatus or the contralateral nuclei fastigii, interpositus and dentatus terminate in these nuclei. Most of them appear to pass beyond the nuclear gray, and the present author is inclined to favor Rasmussen's ('33) interpretation that they do not end in the cerebellar nuclei, instead of Mussen's ('27) decision that some fibers at least do terminate in the contralateral nucleus fastigii and the lateral nuclear group.

As the superior cerebellar peduncle takes form, the majority of the fibers lying dorsal to the cerebellar nuclei on either side turn ventrad passing mostly along the medial surface of the remaining rostral portion of the dentate nucleus; a few sweep over its lateral surface. As both sets of degenerated fibers reach the dorsal border of the peduncle they become more and more compact and lie finally over its dorsolateral surface throughout upper pontine and isthmus levels. When cut in transverse section, they show the typical hook bundle (fig. 14). It should be emphasized that this fasciculus, when occupying this position over the brachium conjunctivum, 
is in reality a sheet of fibers arching dorsolateroventrad around the peduncle for most of its extent, but especially well formed over the caudal two-thirds on the side contralateral to its origin. The uncrossed fibers within Russell's fasciculus are found only over the caudal one-third of the superior cerebellar peduncle (fig. 14).

The crossed ascending limb of the uncinate fasciculus is recognizable in upper pontine regions where it caps and partially intermingles with the superior cerebellar peduncle before the latter begins to decussate (fig. 15). As the dorsal area of the peduncle sweeps ventromediad to enter the commissure of Wernekinck, the degenerated fibers within this ascending limb, although continuing in a cephalad course, also turn slightly medialward and become scattered about equally throughout the thalamo-olivary tract at this level. Their arrangement in the monkey is, as Rasmussen ('33) described them in the cat, in the dorsolateral regions of the reticular (tegmental) formation. They decrease gradually in number as the tract ascends, giving fibers to the surrounding tegmental gray in the isthmus and midbrain regions - crossed fastigio-mesencephalo-motorius fibers and, finally, to the nuclei of the medial longitudinal fasciculus, that is, the interstitial nucleus of Cajal and the nucleus of Darkschewitsch. In this material they cannot be followed beyond levels of the posterior commissure where the remaining fibers end in the region of the nucleus of that commissure. Rasmussen ('33) stated that the fibers of this ascending limb "are finally lost well up in the midbrain" and "Evidently they are distributed to the reticular formation of the upper brain stem."

Rasmussen believed that Probst ('02) observed this ascending limb and termed it "accessorisches Bindearmbündel" but van Gehuchten ('05b) and Allen ('24) interpreted Probst's accessory brachium conjunctivum as a component of the mesencephalic root of the trigeminal nerve. The present author agrees with the interpretation of Rasmussen ('33) for, as Probst ('02) stated, the fibers form a small fascicle in the dorsal part of the reticular substance a little below 
the central gray of the aqueduct, between the dorsal longitudinal fasciculus and the inner margin of the posterior colliculus.

The majority of the fibers in the hook bundle descend ventrad, medial to the inferior cerebellar peduncle and lateral to the superior cerebellar peduncle (fig. 14), to distribute as the crossed descending limb of the bundle to the pons and the medulla oblongata. Although this portion of the fasciculus of Russell forms a conspicuous, compact bundle of fibers when seen in transverse sections it must be remembered that it is dispersed caudocephalad from the level of origin of the brachium conjunctivum to upper pontine regions and thus when the fibers enter the brain stem proper they are spread out from upper levels of the lateral vestibular nucleus to the superior borders of the chief sensory and motor nuclei of the trigeminal nerve (figs. 14 and 15). Passing from this rostral level caudad to the plane of the lateral vestibular nucleus, the following degenerated fibers are observed: (1) bundles arching mediad and entering the dorsal portion of the tegmental gray of the pons - crossed fastigio-pontotegmental fibers; (2) fascicles to the periventricular gray crossed fastigio-ponto-periventricular fibers; (3) bundles to the superior and medial vestibular nuclei - crossed fastigiovestibular fibers; (4) components apparently to the motor nuclei of the trigeminal and abducens nerves - crossed fastigio-ponto-motorius fibers. These last connections represent part of the cerebello-motorius system and the findings are in partial agreement with those of Mussen ('27), who described fibers to the facial nucleus; Rasmussen ('33) did not find any of these latter connections in the cat.

Throughout levels of the lateral 'vestibular nucleus, but after many fibers have ended within this nucleus, some fascicles pass mediad through it into the dorsal portion of the tegmental gray, with a few continuing still farther mediad to enter the medial longitudinal fasciculus where they are lost (figs. 2 and 3). Other bundles, passing caudad, enter the lateral vestibulo-spinal tract, probably contributing fibers to 
the inferior vestibular nucleus in course, and can be followed to mid-inferior olivary levels of the medulla oblongata (fig. 1). In the region of the ponto-medullary junction, fascicles pass either dorsomediad into the periventricular gray as crossed fastigio-medullo and ponto-periventricular fibers or ventromediad into the reticular formation of the medulla oblongata. This last distribution has been observed by many investigators. Contrary to Rasmussen's ('33) results, the available material did not show fibers entering the cervical cord within the lateral vestibulo-spinal fasciculus.

The uncrossed descending limb of Russell's fasciculus consists of fibers which pass dorsad from the lesion in monkey I, partially through the ipsilateral nucleus fastigii, to swing laterad and slightly cephalad, over the ipsilateral nucleus interpositus and dentate nucleus (figs. 2 and 3 ), then ventrad, either on the medial or lateral surfaces of the dentate nucleus, to scatter finally on the dorsolateral surface of the caudal third of the ipsilateral superior cerebellar peduncle (fig. 14). These fibers did not degenerate because of damage to commissural fibers which might have been severed in making the lesion since the approach to the nucleus fastigii and the lesion itself are ventral to the dorsal commissure of the cerebellum and, moreover, the degenerated bundles can be traced easily from this nucleus (figs. 1, 2, and 3).

From the lateral border of the brachium conjunctivum, such fibers pass in two directions: One component swings ventromediad to enter the ventral surface of the superior vestibular nucleus and then to course to and through the lateral vestibular nucleus (fig. 3) finally to reach the periventricular gray in this region where they break up into (1) uncrossed fastigioponto-periventricular fibers, to the periventricular gray of the region; (2) uncrossed fastigio-vestibular fibers to the medial vestibular nucleus; (3) uncrossed fastigio-ponto-tegmental fibers to the dorsal portion of the tegmental pontine gray; and finally (4) into fascicles which approach the medial longitudinal fasciculus. The other component turns caudad in the lateral vestibulo-spinal tract to attain upper and midmedul- 
lary levels where the fascicles gradually disappear (fig. 1). During its descending course, this component probably contributes to the inferior vestibular nucleus; a few fascicles arch ventromediad or dorsomediad to the ventral and dorsal reticular gray as uncrossed fastigio-medullo-reticular fibers. Some fascicles can also be traced into the homolateral nucleus of the abducens nerve (fig. 15), but can be followed to no other ipsilateral motor nuclei. These fascicles might be called uncrossed fastigio-ponto-motorius fibers which again represent part of the large cerebello-motorius system.

The uncrossed tract is less in amount and in extent of distribution than the crossed descending tract of Russell's fasciculus. Furthermore, from the available material, the author could not verify Mussen's ('27) statement that the hook bundle goes to the nucleus of the facial nerve; moreover, there was no suggested relationship with the superior olive or with the cortico-spinal tract.

Fastigio-vestibular system. Rasmussen ('33) believed there was little justification for giving this system a separate name and considered that it should be included in Russell's fasciculus. The present author agrees with Rasmussen that a common term should be used which would include both systems, but disagrees with his selection of the term "uncinate fasciculus of Russell," since the uncinate tract, as generally described in the literature, is limited to fibers which hook over the superior cerebellar peduncle before entering the brain stem at various levels. The fastigio-vestibular (Deiters') system enters the brain stem in a different manner. Therefore, the term fastigio-bulbar system is used in this study to include both the fastigio-vestibular tract and Russell's fasciculus.

The crossed and uncrossed components of the fastigiovestibular tract will be described together because the principal difference between them is merely that the crossed portion has a greater number of fibers. The majority of the degenerated fascicles which comprise either the crossed or uncrossed component arise from the ventral surface of the 
nucleus fastigii (fig. 3) and pass ventrolaterad to either side of the midline, sweeping along the roof of the 4 th ventricle at the widest part of that ventricle. They leave the cerebellum by the juxtarestiform portion of the inferior cerebellar peduncle to enter the brain stem at the pontomedullary junction. Here they turn acutely ventrad and then mediad to enter the lateral (or Deiters') vestibular nucleus (fig. 3). The other component of this system comes from some of the fibers which first pass dorsad from the nucleus fastigii, spread out over the nucleus interpositus and nucleus fastigii on either side, and then pass ventrad between these nuclei to join the other fascicles from the ventral surface of the nucleus fastigii just before leaving the cerebellum (fig. 3). After the degenerated fibers have entered the lateral vestibular nucleus it is impossible to separate them from the crossed and uncrossed components of Russell's fasciculus which have also entered this nuclear area. Some may continue through the lateral vestibular nucleus but are not recognizable in this material.

Fastigio-periventricular fascicles. The author was surprised to note the widespread distribution of fibers from the nucleus fastigii into the central or periventricular gray of the medulla oblongata, the pons, the isthmus, the midbrain and posterior diencephalon. In the guinea pig, Allen ('24) described some fibers from the brachium conjunctivum ascendens entering the central gray of the midbrain in the region of the Edinger-Westphal nucleus but, otherwise, few descriptions of cerebellar connections to the central gray are to be found.

In the caudal end of the diencephalon, and throughout the mesencephalon and isthmus regions, these fastigio-periventricular fibers are completely crossed and the degenerated fascicles are incorporated in the ascending limb of Russell's fasciculus. There is an almost continuous exodus of fibers from the ascending limb which enter the central gray, starting at inferior collicular levels, where the limb caps and intermingles with the superior cerebellar peduncle (fig. 15), and 
continuing to its termination at posterior commissural levels. At isthmus and inferior collicular levels, prior to the decussation of the superior cerebellar peduncle, the fascicles enter the central gray by arching dorsomediad through the mesencephalic root of the trigeminal nerve to distribute to pars lateralis and pars ventralis of the periventricular gray, and to the lateral wing and central portions of the dorsal nucleus of the raphé. After the decussation of the dorsal half of the superior cerebellar peduncle, the degenerated fascicles of the ascending limb pass dorsad within the region of the thalamo-olivary tract, and in this position fascicles pierce the ventral surface of the periventricular gray and distribute to the inferolateral quadrant of this gray throughout superior collicular levels. Farther cephalad, the distribution to pars ventralis and pars lateralis of the periventricular gray continues but, in addition, fibers pass to the nucleus parvocellularis annuli aquaeductus and to the nucleus of Darkschewitsch. Just lateral to the central gray the degenerated fascicles terminate in the region of the nucleus of the posterior commissure and the interstitial nucleus of the medial longitudinal fasciculus.

There is a predominance of crossed fastigio-ponto-periventricular fibers (figs. 2 and 3). The degenerated fascicles, whether they be crossed or uncrossed, all enter the periventricular gray by arching dorsomediad from the main bundle of fibers of the fastigio-bulbar tracts. They enter the lateral edge of the periventricular gray and then course just under the floor of the 4th ventricle within this gray to terminate. These fibers do not distribute to the efferent nuclei of the cranial nerves.

In the medulla oblongata, the author found only crossed fastigio-periventricular fibers, although, of course, there may be uncrossed fibers as well. As the lateral vestibulo-spinal tract descends in the dorsolateral regions of the medulla oblongata, degenerated fascicles lie within its boundaries. Throughout upper and midmedullary levels, fibers leave this tract by arching dorsomediad to enter the lateroventral sur- 
face of the periventricular gray (fig. 3). As in the case of the crossed fastigio-periventricular fibers of the pons, these medullary fibers also distribute throughout the periventricular gray without apparently terminating in any of the efferent nuclei of the cranial nerves.

\section{DISCUSSION}

Severe symptomatology is produced in the macaque by bilateral section of the superior cerebellar peduncle and the effects are more marked than those resulting from a summation of the symptoms produced from two separate unilateral sections of a superior cerebellar peduncle (Walker and Botterell, '37). In contrast is the almost complete lack of disturbance with small lesions in the cerebellar nuclei or cerebellar cortex. The explanation for these differences seems to depend upon the ability of one portion of the cerebellar gray to compensate, within reasonable limits, for another similar portion of this brain area. Thus, separate portions of one cerebellar nucleus or two separate cerebellar nuclei which have like function (as have been determined by experimental stimulation studies of various investigators) send crossed and/or uncrossed fibers to the same brain stem or thalamic center and reach it directly or after a synapse in course. Consequently, a specific nuclear center within the brain stem or the thalamus may receive impulses from several portions of the same cerebellar nuclear area or from functionally similar cerebellar nuclei.

Several examples will serve to illustrate these points. Mussen ('27) placed small, discrete lesions in the dorsocephalic portions of the dentate and emboliform nuclei and traced the distribution of the degenerated fibers to the magnocellular and parvocellular parts of the red nucleus, the field of Forel and the ventral nucleus of the dorsal thalamus on the side opposite the lesion. In the present material a lesion produced in the medial portion of the caudal two thirds of the dentate nucleus (fig. 4) resulted in a distribution of degenerated fibers to the contralateral midbrain and thalamic areas which, in 
part, have a similar distribution to that described by Mussen. Fibers terminated in both portions of the contralateral red nucleus (figs. 9 and 10), the tegmental field of Forel (fig. 11) and throughout the lateral part of the ventral nucleus of the dorsal thalamus. In addition, as previously described under the section dealing with the dento-thalamic tract, there were other connections which Mussen did not discuss. However, it seems clear that the mediocaudal portion and the dorsocephalic part of the dentate and emboliform nuclei project, at least in part, to the same areas within the red nucleus, the field of Forel and the dorsal thalamus. The present author does not mean to imply that this duplication of distribution of fibers from different areas of the dentate and emboliform nuclei is completely similar, but there is probably enough overlap in connections to allow for partial or even complete compensation of function when one area of the dentate or of the interpositus nucleus alone is destroyed.

A comparable situation exists for the nucleus fastigii. Although Mussen ('27) did not describe the exact extent or position of the lesion which he placed in this nucleus, it can be seen from his photomicrographs that the greatest extent was in the dorsolateral portion of the caudal part of the nucleus. The lesion in monkey I was in the medioventral area of the caudal two-thirds of the nucleus fastigii (figs. 1, 2 and 3 ). Even though there is some obvious overlap in the site of the lesion in his series, and also in the present series, it would appear that the dorsolateral area of the nucleus fastigii has a distribution similar to that of its ventromedial portion. Therefore, it follows that one should not expect to observe lasting clinical manifestations from small lesions of the cerebellar nuclei of the macaque.

The Klimoff-Wallenberg fibers, which arise in part from the dentate nucleus (series 2) and pass to the contralateral oculomotor nucleus after crossing in the decussation of the superior cerebellar peduncle, represent a direct anatomical projection to the eye muscle nucleus. In addition, there are fibers from the same area of the dentate nucleus to the con- 
tralateral nucleus of Darkschewitsch and the interstitial nucleus of the medial longitudinal fasciculus (fig. 10) which, in turn, give rise to crossed and uncrossed fibers that also terminate by way of the medial longitudinal fasciculus in the oculomotor nuclei. Thus, there is an indirect effect, as well as a direct influence, on the same midbrain center from the same region of the dentate nucleus. Whether this indirect type of innervation can compensate for a loss of direct cerebellar influence cannot be stated from the present material; nevertheless, the possibility does exist. If, on the one hand, only the direct fibers are destroyed, the indirect innervation from the opposite dentate nucleus may be able to send an adequate discharge to the oculomotor nucleus via the medial longitudinal fasciculus to maintain normal, or almost normal, function of this center as regards cerebellar influence upon it. On the other hand, if both the direct and the indirect connections are removed in a single animal, the resultant disturbance would probably be greater than the sum of the disabilities exhibited by two animals, one of which has the loss of the direct and the other of the indirect cerebellooculomotor projection. Undoubtedly the loss of direct cerebellar connection is more important than that of the indirect.

In this material it has been possible to confirm the generally accepted terminations of the efferent fibers of the cerebellar nuclei as described in the literature. In addition, the controversial points regarding the terminations of certain efferent cerebellar fibers such as fascicles to the medial and midline nuclei of the dorsal thalamus to the zona incerta and to the field of Forel (fig. 11) have been clarified. Moreover, in the monkey the present writer found hitherto undescribed crossed and uncrossed fibers to the periventricular gray of the midbrain (in association with its specific nuclear groups), of the pons and of the medulla oblongata; crossed fibers to the nucleus of Darkschewitsch and the interstitial nucleus of the medial longitudinal fasciculus; crossed and uncrossed fibers to all parts of the nucleus mesencephalicus profundus; and crossed fibers, within the brachium conjunc- 
tivum descendens, to the medial and dorsal accessory olivary nuclei and to the chief inferior olivary nucleus.

It is well known that other important centers of the central nervous system such as the basal ganglia, the cerebral cortex, the hypothalamus and the subthalamic areas may also project fibers, either directly or indirectly, to all or nearly all of the previously mentioned regions in which the efferent fibers of the cerebellum terminate. The regions or nuclear masses which have these multiple connections might well be designated as correlating centers and their efferent tracts thought of as final common pathways for the resultant discharge of the interaction of the various centers concerned. The total number of cerebellar efferent fibers, both crossed and uncrossed, from the pairs of cerebellar nuclei to these correlating centers is very large. In the present study their scope of termination throughout the brain stem and thalamus has been broadened.

The medial longitudinal fasciculus, which represents in part one of the extrapyramidal systems, has within it crossed and uncrossed fibers which arise from both the nucleus of Darkschewitsch and the interstitial nucleus of this fasciculus and descend throughout the brain stem levels into the cervical cord. In course, connections are established with the motor nuclei of the oculomotor, the trochlear and the abducens nerves as well as with other efferent motor nuclei. Woodburne, Crosby and McCotter ('46) have stressed the connections from the dorsomedial portions of the globus pallidus by way of the $\mathrm{H}_{2}$ bundle of Forel (fasciculus lenticularis) to the nucleus of Darkschewitsch and the interstitial nucleus of the medial longitudinal fasciculus. In the present material it can be demonstrated that both the dentate and fastigial nuclei send fibers to the contralateral nucleus of Darkschewitsch and to the interstitial nucleus of the medial longitudinal fasciculus. Thus, these two nuclei might be designated as correlating centers as regards the cerebellum and the basal ganglia, and the fibers passing into the medial longitudinal fasciculus from them might be considered a final common pathway. 
Another such correlating center is the periventricular gray of the brain stem. Its various intrinsic nuclear groups are connected with efferent cerebellar fibers and with the dorsal longitudinal fasciculus which arises partly in the hypothalamus and partly by synapses in its course (Crosby and Woodburne, '51). It is concerned with hypothalamic discharge to the parasympathetic nuclear masses in the brain stem and also to the nuclear groups innervating striated muscle supplied by cranial nerves. It is difficult to evaluate, with our present day knowledge, the exact influence of the cerebellum upon these combined motor and parasympathetic systems; it may be that it affects only the areas discharging to striated muscle. Nevertheless, such striated muscles, many of them of branchiomeric origin, are coordinated in activity with the structures supplied by the parasympathetic system. It has long been recorded that the reticular substance of the medulla oblongata is concerned, at least in part, with the sympathetic nervous system and that it receives many cerebellar connections. Again, just how these connections influence the centers under the regulation of the sympathetic system remains obscure.

The clinical symptoms resulting from lesions involving the efferent fibers of the cerebellar nuclei represent a loss of cerebellar influence upon appropriate motor centers, directly or indirectly, and a deficit in the balanced interaction between the cerebellum and other regions of the central nervous system through correlating centers. The severity of the symptoms depends, to a large extent, upon the amount of involvement of the efferent fibers which in turn is limited by the site and the size of the lesion.

Most investigators believe that the general function of the cerebellum is to coordinate motor activity through its interaction with other regions of the central nervous system. Tilney ('19) was in accord with this when he stated that the principal function of the cerebellum is synergia, which he felt was dependent on "the establishment and maintenance of synergic muscular units throughout the body" and "the es- 
tablishment and maintenance of coordination between the synergic units." Therefore, he believed that all symptoms arising from cerebellar dysfunction are manifestations of asynergia. The significance of correlating centers and their final common pathways is, the present author believes, to be found in Tilney's principle of synergia. The combined effective action of the cerebellum upon one or more of the other centers of the central nervous system, such as the basal ganglia, acting through its related correlating centers, produces an appropriate motor action which aids in "the establishment and maintenance of coordination between the synergic units" and thus brings about normal motor activity.

\section{SUMMARY}

1. Experiments upon 4 macaques are the basis for this study. In two animals small lesions were placed in the dentate and fastigial nuclei respectively; in the other two monkeys larger lesions were made in the lateral nuclear groups of the cerebellum and included all or part of the ipsilateral superior cerebellar peduncle. A mild cauterizing electrical current was used to produce all of these lesions.

2. The cerebellar nuclei consist of a continuous mass of gray. At least in the monkey, the anatomical subdivisions of this nuclear gray are limited to a lateral and a medial cerebellar nucleus on each side of the brain. The medial portion of the dentate, as seen in caudal sections, becomes the lateral part of the interpositus nucleus at more rostral levels. The fastigial nucleus shows no evidence of true anatomical subdivision. Certainly further subdivisions than those made by Brunner ('19) for the monkey are not justified.

3. It has been possible to confirm the generally accepted terminations of efferent fibers of the cerebellar nuclei, to give support to some efferent cerebellar systems which have been a subject for controversy on the part of various investigators, and, in addition, to demonstrate in the monkey: (a) a previously undescribed distribution of crossed and uncrossed fibers to the periventricular gray of the midbrain, the pons 
and the medulla oblongata, (b) crossed bundles to the nucleus of Darkschewitsch and the interstitial nucleus of the medial longitudinal fasciculus, (c) crossed and uncrossed fibers to all parts of the nucleus mesencephalicus profundus, (d) and crossed fascicles within the brachium conjunctivum descendens to the medial and dorsal accessory olivary nuclei and to the chief inferior olivary nucleus.

4. The brachium conjunctivum ascendens and brachium conjunctivum descendens appear to have a pattern of distribution, the first to centers in the mesencephalon and the diencephalon, and the second to the pons and the medulla oblongata.

5. Different portions of a single cerebellar nueleus, or of two cerebellar nuclei which have like function as determined by experimental studies, send fibers directly or after a synapse in course to the same brain stem or thalamic centers. As a consequence of this overlap in termination, a specific nuclear center within the brain stem or the thalamus may receive impulses from several portions of the same cerebellar area or from functionally similar portions of different cerebellar nuclei. Thus a small lesion of a cerebellar nucleus shows only transient symptoms; to produce lasting and severe symptoms a considerable part of a cerebellar nucleus, or a large number of efferent fibers, must be involved.

6. Regions of nuclear masses within the brain stem or thalamus which have multiple connections with various areas such as the basal ganglia, the cerebral cortex, the hypothalamus and the cerebellum are correlating centers and their efferent tracts constitute final common pathways which conduct impulses representing the resultant of this correlation.

7. The significance of these correlating centers and their final common pathways is to be found in Tilney's principle of synergia. The combined effective action of the cerebellum and the other centers of the central nervous system brought about in these correlating centers produces an appropriate and normal motor action. 


\section{LITERATURE CITED}

ALLEN, W. F. 1924 Distribution of the fibers originating from the different basal cerebellar nuclei. J. Comp. Neur., 36:399-439.

ARIËNS KAPPERS, C. U. 1921 Die vergleichende Anatomie des Nervensystems der Wirbeltiere und des Menschen. II. Absehnitt. De Erven F. Bohn, Haarlem. 1329 p.

Aryëns Kappers, C. U., G. C. Huber AND E. C. Crosby 1936 The comparative anatomy of the nervous system of vertebrates, ineluding man. The Macmillan Co., New York. 2 vols. 1845 p.

BrunNer, H. 1919 Die zentralen Kleinhirnkerne bei den Säugetieren. Arb. a.d. Neur. Inst. a.d. Wien. Univ., 22: 200-277.

Castaldi, L. 1923 Studi sulla struttura e sullo sviluppo del mesencefalo. Richerche in Cavia cobaya. Arch. Ital. Anat. e Embr., 20: 23-225.

CLARK, W. E. LE GRos 1936 The termination of ascending tracts in the thalamus of the macaque monkey. J. Anat., London, $\gamma 1: 7-40$.

ClaRke, R. H., AND V. HoRSLFY 1905 On the intrinsic fibers of the cerebellum, its nuclei and its efferent tracts. Brain, $28: 13-29$.

Crosiy, E. C., AND R. T. Woodburne 1943 The nuclear pattern of the nonteetal portions of the midbrain and isthmus in primates. J. Comp. Neur., 78: 441-482.

1951 The mammalian nidbrain and istlımus regions. Part II. The fiber connections. C. The hypothalamo-tegmental pathways. J. Comp. Neur., 94: 1-32.

Crovch, R. L., AND J. K. Thompson 1938 Termination of the brachium conjunetivum in the thalamus of the macaque monkey. J. Comp. Neur., $69: 449-452$.

DEMolÉ, V. 1927 Structure et connexions des noyaux dentelés du cervelet. Sehweiz. Areh. f. Neur. u. Psychiatr., 20: 271-294.

Domenico, M. 1899 Quoted from Gehuchten, 1905a.

Dow, R. S. 1942 The evolution and anatomy of the cerebellum. Biol. Rev, $17: 179-220$.

Dowd, L. W. 1929 The development of the dentate nucleus in the pig. J. Comp. Neur., 48: 471-499.

Ferrier, D., and W. A. Turnter 1894 A reeord of experiments illustrative of the symptomatology and degeneration following lesions of the cerebellum and its peduncles and related structures in monkeys. Phil. Trans. Roy. Soc. London, 185: 719-778.

Forx, C., ANd J. Nicolesco 1925 Anatomie cérébrale. Les noyaux gris centraux et la région mésencéphalo-sonsoptique. Masson et Cie., Paris. 581 p.

FOrEL, A. 1881 Quoted from Gehueliten, 1905a.

Gehuchten, A. van 1905a Les pédoncules cérébelleux supérieurs. Le Névraxe, $7: 29-86$.

1905b Le faisceau en crochet de Russell ou faisceau cérébellobulbaire. Le Névraxe, 7 : 117-159.

Gerebtzofr, M. A. 1936 T.e pédoneule cérébelleux supérieur et les terminaisons réelles de la voie cérébello-thalamique. Mem. Acad. Med. Belg., 25: $1-58$. 
Harschek, R. 1907 Zur vergleichenden Anatomie des Nucleus ruber tegmenti. Arb. a. d. neur. Inst. a. d. Wien. Univ., 15: 89-136.

HohmaN, L. B. 1929 The efferent connections of the cerebellar cortex; investigations based upon experimental extirpations in the cat. The Cerebellum. Res. Publ. Ass. nerv. ment. Dis., 6: 445-460. The Williams and Wilkins Co., Baltimore.

Horsley, V., AND R. H. ClaAkE 1908 The structure and functions of the cerebellum examined by a new method. Brain, 31: 45-124.

Huber, G. C. 1927 New method of fixation and staining of the central nervous system for the purpose of study of cytoarchitecture. Contributions to Medical Science. (Dedicated to Alfred Scott Warthin.) pp. 1-12. Ann Arbor, Michigan.

Jansen, J., AND A. Brodal 1940 Experimental studies on the intrinsic fibers of the cerebellum. II. The corticonuclear projection. J. Comp. Neur., 73: $267-321$.

KLimoff, J. 1899 Ueber die Leitungsbahnen des Kleinhirns. Arch. f. Anat. u. Physiol., Anat. Abt., S. 11-26.

Lewandowsky, M. 1903 Beiträge fur Anatomie des Hirnstammes. J. f. Psychol. und Neur., 2: 18-30.

Magoun, H. W., W. K. HaRe aNd S. W. Ranson 1935 Electrical stimulation of the interior of the cerebellum in the monkey. Am. J. Physiol., 11.2: $329-339$.

MARBURG, O. 1924 Entwicklungsgeschichte, makroskopische und mikroskopische Anatomie des Nervus cochlearis, vestibularis und Kleinhirns sowie der zugehörigen Abschnitte des centralen Nervensystems (Centren und Bahnen). Handbuch der Neurologie des Ohres. Urban and Schwarzenberg, Berlin and Wien. Vol. I. S. 175-336.

MARCHI, V. 1892 Sur l'origine et le cours des pédoncules cérébelleux et sur leurs rapports avec les autres centres nerveux. Arch. Ital. de Biol., 17: $190-201$.

Mingazini, G. 1928 Das Mittelhirn. In W, von Möllendorf's Handbueh der mikroskopischen Anatomie des Menschen. Bd. 4, S. 644-673. J. Springer, Berlin.

MONAKow, C. von 1910 Der rote Kern, die Haube und die Regio hypothalamica bei einigen Säugetieren und beim Menschen. Arb. a. d. hirnanat. Inst. Zürich, 4 : 103-225.

Mussen, A. T. 1927 Experimental investigations on the cerebellum. Brain, $50: 313-349$.

Orestano, F. 1901 Le vie cerebellari efferenti. Rivista di patologia nervosa e mentale. $6: 49-69$.

Prosst, M. 1902 Zur Anatomie und Physiologie des Kleinhirns. Arch. f. Psychiat., 35: 692-777.

RaMón Y CAJAT, S. 1903 La doble vía descendente nacida del pedúnculo cerebeloso superior. Trabajos del laboratorio de investigaciones biologicas de la Universidad de Madrid, N. Moya, Madrid, 2 : 23-29.

1904 Textura del sistema nervioso del hombre y de los vertebrados. T. II, Primera Parte. 608 p. N. Moya, Madrid. 
RAMón y CaJaL, S. 1911 Histologie du système nerveux de l'homme et des vertébrés. T. 2, 993 p. A. Maloine, Paris.

Ranson, S. W., AND W. R. Ingram 1932 The diencephalic course and termination of the medial lemniseus and brachium conjunctivum. J. Comp. Neur., 56:257-275.

RASmUSsen, A.T. 1933 Origin and course of the faseiculus uncinatus (Russell) in the eat, with observations on other fiber tracts arising from the cerebellar nuclei. J. Comp. Neur., 57: 165-197.

RUSSELL, J. S. RISIEN 1895 Degeneration consequent on experimental lesions of the cerebellum. Phil. Trans. Roy. Soc. London, 186:633-660.

SACHS, E. 1909 On the strueture and funetional relations of the optie thalamus. Brain, 3: : 95-186.

Sachs, E., AND E. F. Fincher 1927 Anatomical and physiologieal observations on lesions in the cerebellar nuelei in Macacus rhesus. Brain, 50 : $350-356$.

Sriluina, B. 1867 Untersuchungen über den Bau des Centralläppchens und der Flügel. T. Kay, Cassel.

1878 Neue Untersuchungen über den Bau des kleinen Gehirns des Menschen. T. Fischer, Cassel.

SWANK, R. L., AND H. A. DAVENPORT 1935 Chlorate-osmic-formalin method for staining degenerating myelin. Stain Tech., 10: 87-90.

Thomas, A. 1897 Le cervelet. Paris, G. Steinheil. 353 p.

TILNEY, F. 1919 The functional signifieance and principal syndrome of the cerebellum. Neur. Bull. Parts I and II, 2: 289-312.

1927 The ehief intracerebellar and precerebellar nuclei, with a demonstration of models and charts. Brain, 50:275-276.

VoGT, C. 1909 La myéloarchitecture du thalamus du cercopithèque. J. f. Psychol, u. Neur., 19: 285-324.

Walker, A. E. 1938a The primate thalamus. Univ. of Chicago Press, Chicago, III. $321 \mathrm{p}$.

$1938 \mathrm{~b}$ The thalamus of the chimpanzee. I. Terminations of the somatie afferent systems. Confinia Neur., 1: 99-127.

WhLker, A. E., ANd E. H. Botrerell 1937 The syndrome of the superior eerebellar peduncle in the monkey. Brain, $60: 329-353$.

Wallenderg, A. 1898 Die secundäre Acusticusbahn der Taube. Anat. Anz., 14: $353-372$.

WeIl, A. 1945 Textbook of neuropathology. Second ed., Grune \& Stratton, New York. $356 \mathrm{p}$.

Woodburne, R. T., E. C. Crosby and R. E. MeCotter 1946 The mammalian midbrain and isthmus regions. Part II. The fiber connections. A. The relations of the tegmentum of the midbrain with the basal ganglia in Macaca mulatta. J. Comp. Neur., 85: 67-92. 


\section{PLATES}

\section{ABBREVIATIONS}

ABD. N., abducens nerve

ABD. NUC., abducens nucleus

ACOUS. N., acoustic nerve

$A Q$., aqueduet

ARC. F., arcuate fibers

ASC. L. RUSS. FAS., ascending limb of Russell's fasciculus

BR. CONJ., brachium conjunetivum

BR. CONJ. DES., brachium conjunetivum descendens

CENT. MED. NUC., centromedian nucleus

CEREB. VEST. F., cerebello-vestibular fibers

CER. PED., cerebral peduncle

DARK. NUC., nucleus of Darksehewitsch

IEC. BR. CONJ., decussation of brachinm conjunctivum

DENT. NUC., dentate nucleus

FAST, FLOCC. F., fastigio-floccular fibers

FAST. NUC., nucleus fastigii

FOREL FIELD, field of Forel

INF. CEREB. PED., inferior cerebellar pedunele

INF. COLL., inferior colliculus

INF. OL., inferior olive

INTERPOS. NUC, interpositus nucleus

INT. NUC. M.L.F., interstitial nucleus of medial longitudinal fasciculus

LAT, DORS. TEG. NUC., lateraldorsal tegmental nucleus
LAT. VEST. NUC., lateral vestibular nucleus

LAT. VEST. SP. TR, lateral vestibulo-spinal tract

LESION, lesion

MED. LEM., medial lemniscus

M.L.F., medial longitudinal fasciculus

MED. RET. GR., medial reticular gray

MED. VEST. NUC., medial vestibular nucleus

MES. ROOT TRIG., mesencephalic root of trigeminal

MIDLINE NUC., midline nuclei

NUC. VENT. POST., nucleus ventralis posterior of dorsal thalamus

OCULO. N., oculomotor nerve

OCULO. NUC, oculomotor nucleus

PERIVENT. GR., periventricular gray

PYR., pyramid

RED NUC., red nucleus

RUSS. FAS., CR., Russell's faseiculus, crossed

RUSS. FAS., UNCR., Russell's fasciculus, uncrossed

SENS. TRIG. NUC, sensory trigeminal nucleus

SUB. NTG., substantia nigra

SUP. CEREB. PED, superior cerebellar peduncle

SUP. VEST. NUC., superior vestibular nucleus

VENT. IV, 4th ventriele

VERM., vermis cerebelli 


\section{PLATE 1}

\section{EXPLANATION OF FIGURES}

1 Photomicrograph of medulla oblongata and cerebellum (monkey I) showing caudal extent of lesion in right nucleus fastigii. Degenerated fibers passing to flocculus and within lateral vestibulo-spinal tract. Marchi stain. $\times 7$.

2 Photomicrograph of lower pons and cerebellum (monkey I) showing lesion in medioinferior quadrant of right nucleus fastigii. Degenerated fibers dorsaj and lateral to cerebellar nuclei and within the lateral vestibular nuclei, the periventricular gray and tegmentum. Marchi stain. $\times 7$.

3 Photomicrograph of rostral extent of lesion in right nucleus fastigii (nomkey I). Demonstrates cerebello-vestibular fibers and Russell's crossed fasciculus. Marchi stain. $\times 7$. 


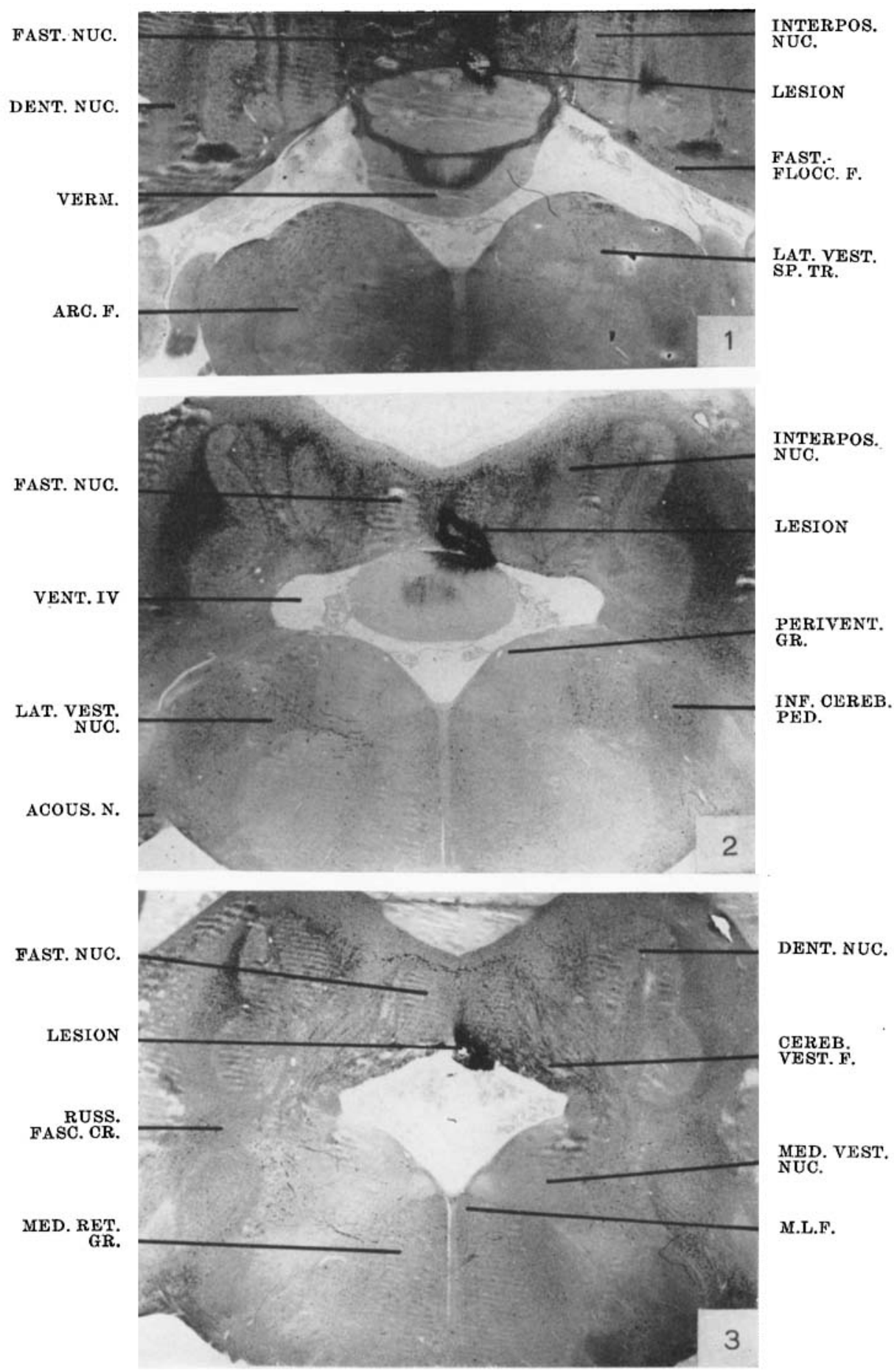




\section{PLATE 2}

FXPLANATION OF FIGURTS

4 and 5 Photomicrographs of left dentate nucleus (monkey II) showing size and extent of lesion with escape of degenerated fibers from hilus of dentate nucleus. Marchi stain. $\times 7$.

6 Plotomicrograph demonstrating degenerated fibers passing mediad in brachium conjunetivum maintaining their central position; completely crossed degenerated fascieles in brachium conjunetivum descendens (monkey II). Marchi stain. $\times 12$. 

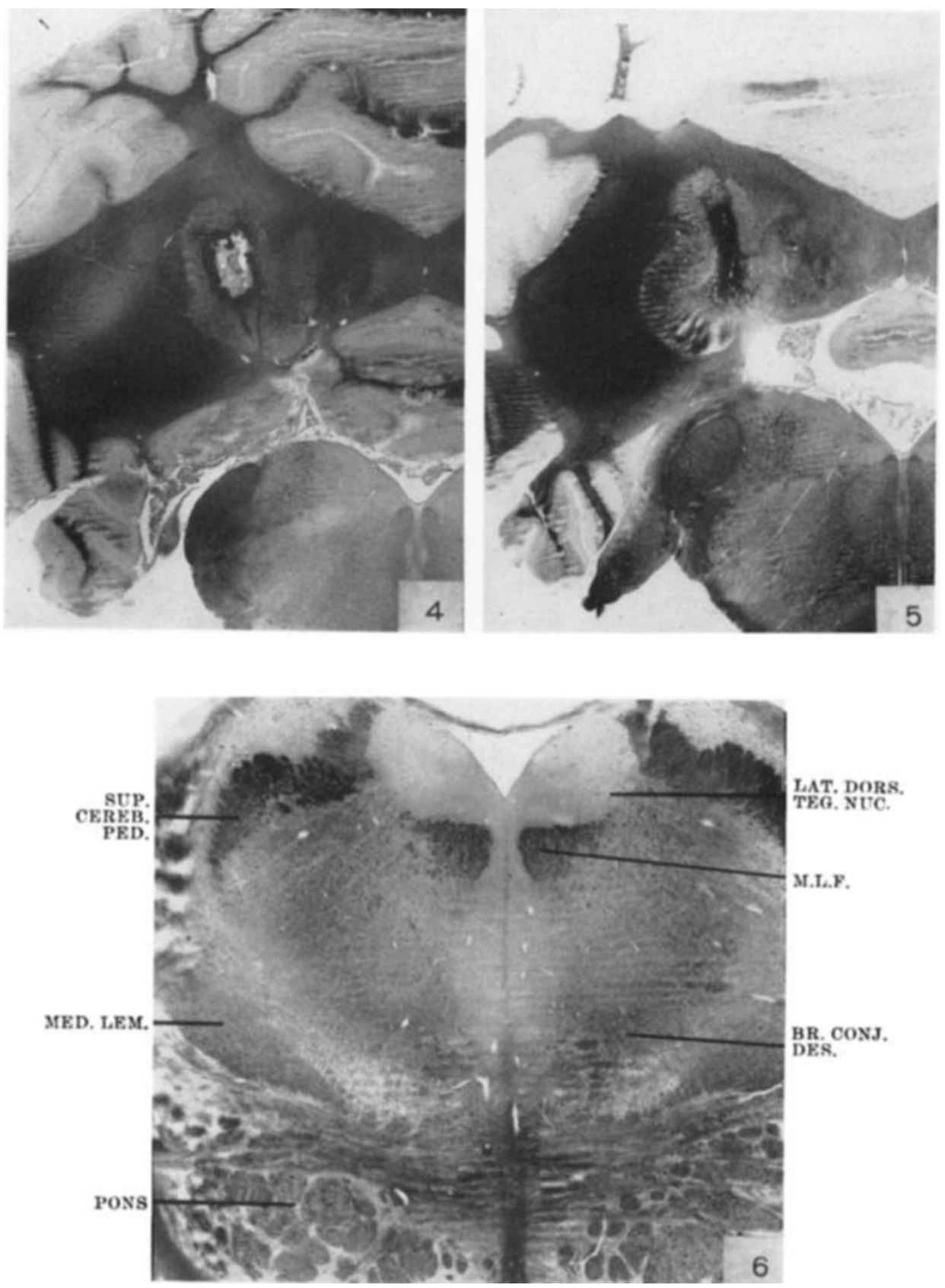
PLATE 3

EXPLANATION OF FIGURES

$7 \mathrm{~A}-\mathrm{F}$ Photomicrographs of various planes of the cerebellar nuclei illustrating their changing configurations in transverse sections. Toluidine blue and Weil stains. $\times 18$. 

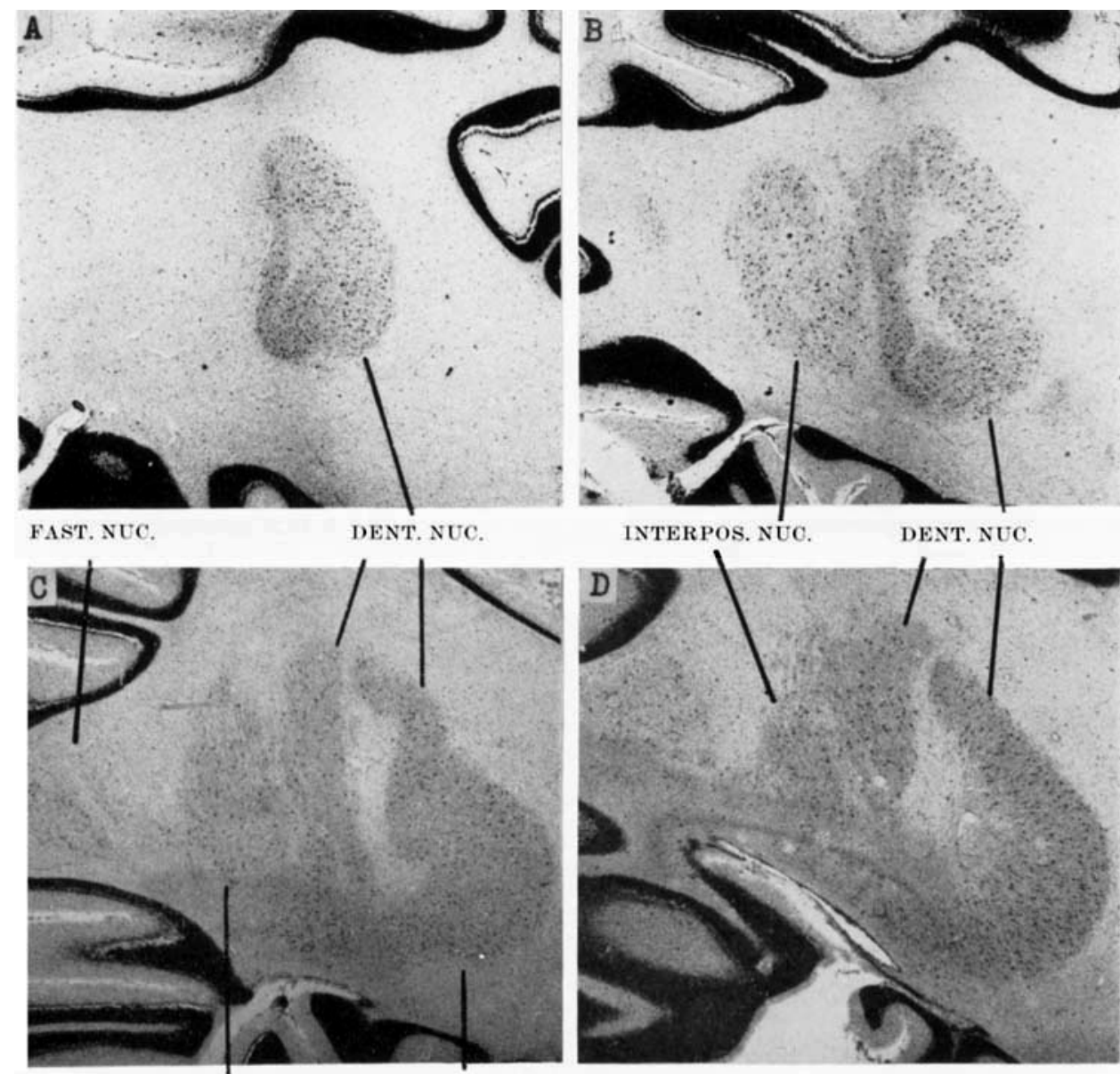

INTERPOS. NUC. DENT. NUC.
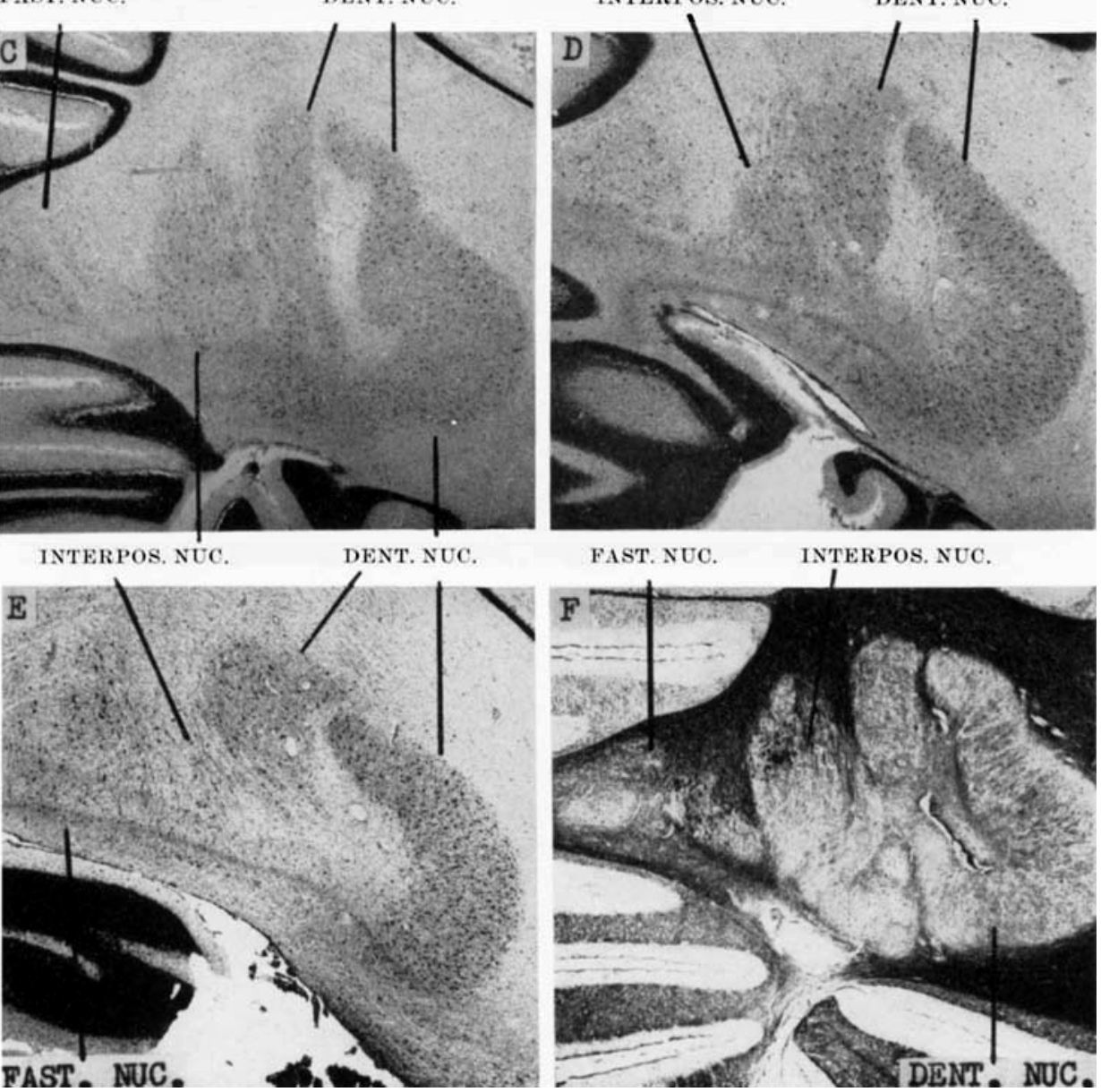

FAST. NUC.

INTERPOS. NUC.

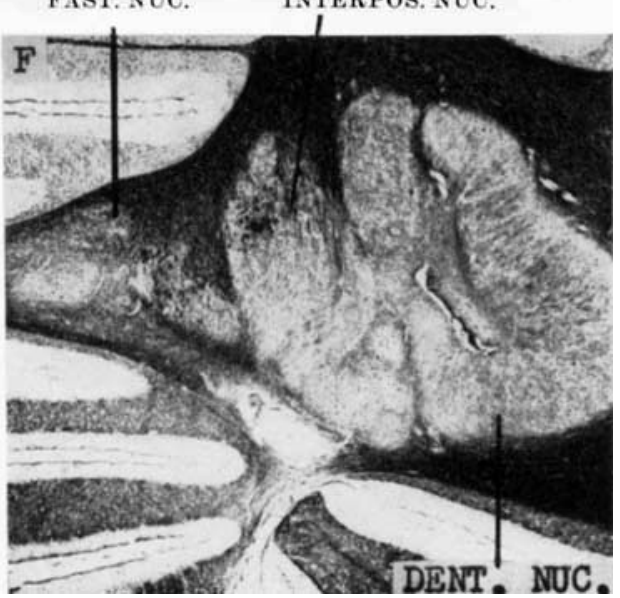




\section{PLATE 4}

EXPLANATION OF FIGURES

8 Photomicrograph at inferior collicular levels showing step-like manner of decussation of superior cerebellar peduncle and degenerated fibers in the brachium conjunctivum descendens (monkey II). Marchi stain. $\times 12$.

9 Photomicrograph of degenerated fascicles within and surrounding the red nucleus. Note complete absence of unerossed fibers to red nucleus - decussation is complete at this level (monkey II). Marchi stain. $\times 12$.

10 Photomicrograph of fibers lying ventral and dorsolateral to the red nucleus with distribution to the periventricular gray and to the nucleus of Darksehewitsch and the nucleus of the medial longitudinal fasciculus (monkey II). Marchi stain. $\times 12$. 

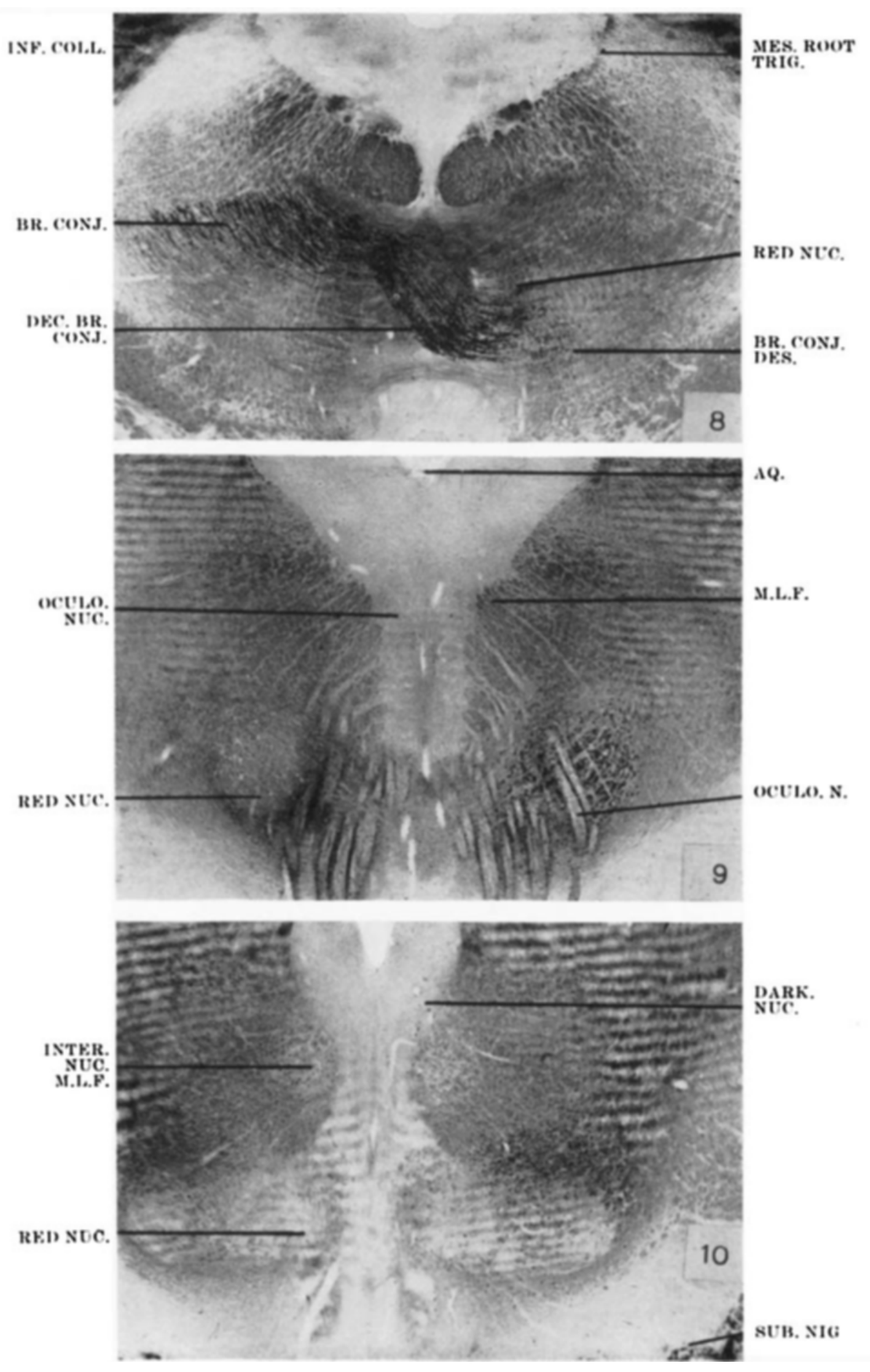
PLATE 5

EXPLANATION OF FIGURES

11 Photomicrograph of diencephalon of monkey III demonstrating increased distribution of degenerated fibers en route to the nucleus ventralis lateralis and to the medial and midline thalamic nuclei. Marchi stain. $\times 12$.

12 Photomicrograph illustrating degeneration within the right brachium conjunctivum and also in the dorsal portion of the left brachium conjunctivum. Degenerated fascicles in both brachia conjunctiva descendentes; those from the dorsal portion of the left superior cerebellar peduncle lie in the dorsolateral portion of. the right brachium eonjuncidvum descendens (monkoy IV). Marchi stain. $\times 10$.

13 Photomicrograph of medulla oblongata of monkey III illustrating degenerated fascicles within the brachium conjunctivum descendens distributing to the inferior olivary nuclei. Degenerated fibers within the left lateral vestibulo-spinal tract are a result of lesion in left latera] vestibular nucleus. Marchi stain. $\times 7$. 


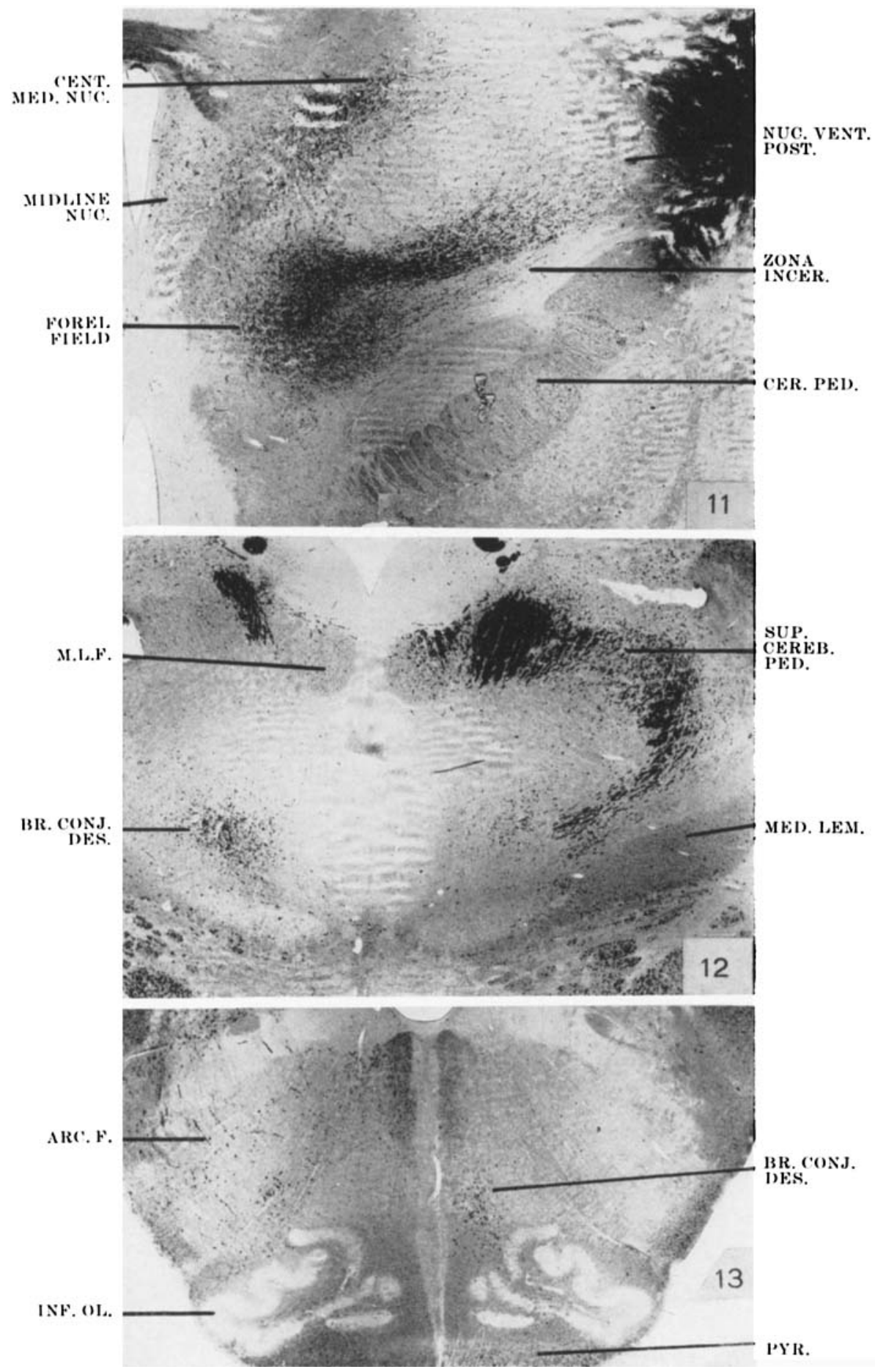


PLATE 6

EXPLANATION OF FIGURES

14 Photomierograph of lower level of abducens nerve (monkey I) illustrating Russell's uncinate fasciculus (crossed and uncrossed bundles). Degenerated fascicles to superior vestibular nuelei, abducens nuclei and periventricular gray. Brachium conjunetivum is forming. Marchi stain. $\times 7$.

15 Photomicrograph at level of trigeminal nucleus illustrating ascending limb of Russell's fasciculus capping and intermingling with the left superior cerebellar' peduncle (monkey I). Degenerated fibers to motor nucleus of left trigeminal nerve and to tegmental gray. Marchi stain. $\times 7$. 

ROBERT: WHEETIER RAND
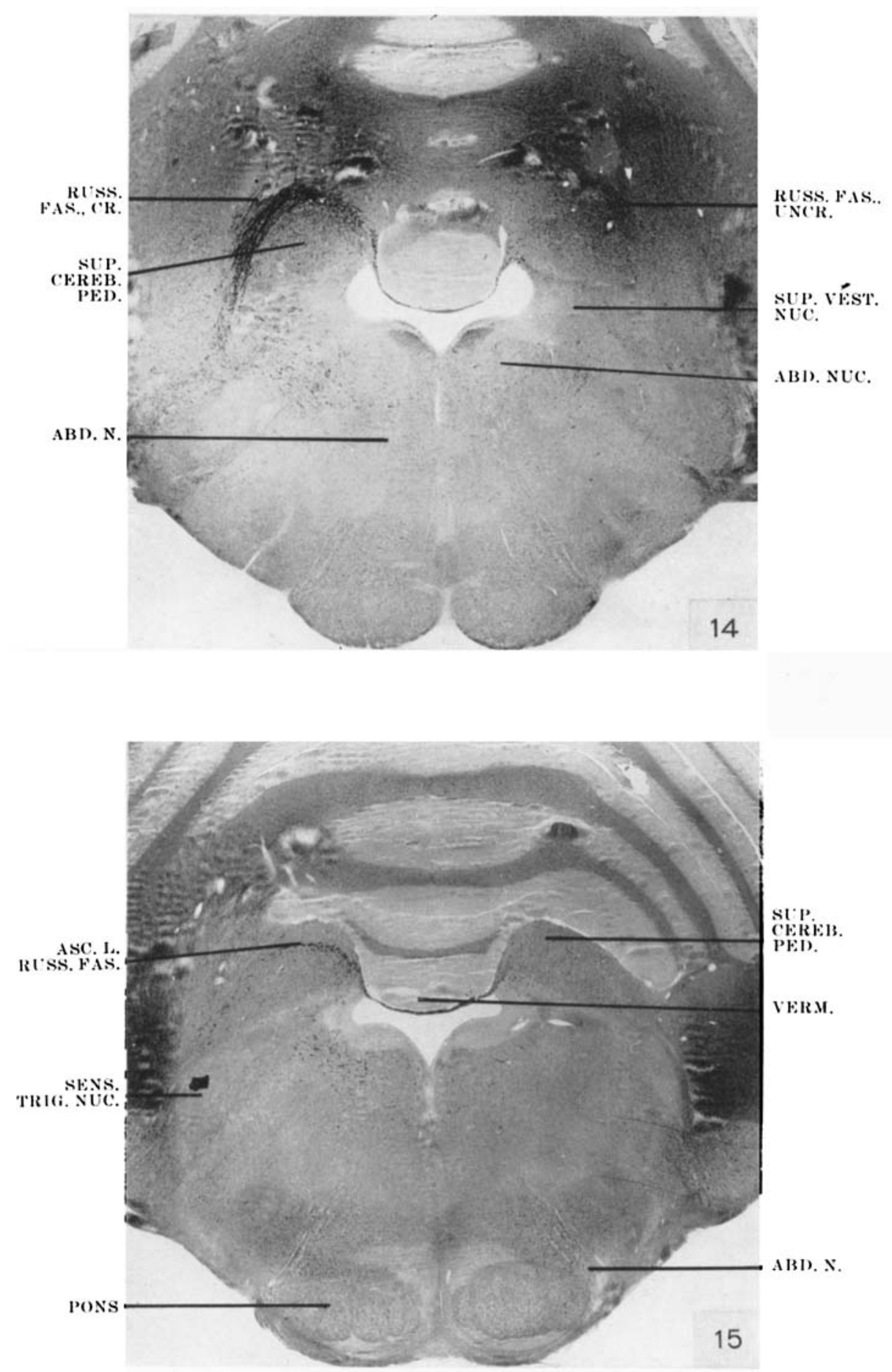